\title{
An Overview of Ares-I CFD Ascent Aerodynamic Data Development And Analysis Based on USM3D
}

\author{
Khaled S. Abdol-Hamid*, Farhad Ghaffari* \\ NASA Langley Research Center \\ Hampton, Virginia \\ And \\ Edward B. Parlette \\ Vigyan, Inc. \\ Hampton, Virginia
}

\begin{abstract}
An overview of the computational results obtained from the NASA Langley developed unstructured grid, Reynolds-averaged Navier-Stokes flow solver USM3D, in support of the Ares-I project within the NASA's Constellation program, are presented. The numerical data are obtained for representative flow conditions pertinent to the ascent phase of the trajectory at both wind tunnel and flight Reynolds number without including any propulsion effects. The USM3D flow solver has been designated to have the primary role within the Ares-I project in developing the computational aerodynamic data for the vehicle while other flow solvers, namely OVERFLOW and FUN3D, have supporting roles to provide complementary results for fewer cases as part of the verification process to ensure code-to-code solution consistency. Similarly, as part of the solution validation efforts, the predicted numerical results are correlated with the aerodynamic wind tunnel data that have been generated within the project in the past few years. Sample aerodynamic results and the processes established for the computational solution/data development for the evolving Ares-I design cycles are presented.
\end{abstract}

\section{Nomenclature}

$\begin{array}{ll}\text { ADAC Ares-I Design Analysis Cycle } \\ \text { BDM } & \text { Booster Deceleration Motors } \\ \text { BTM } & \text { Booster Tumble Motors } \\ \text { Dia } & \text { First stage diameter, ft } \\ \text { C1 } & \text { ADAC-2A with full protuberances } \\ \mathrm{C} 2 & \text { ADAC-2A with simplified protuberances } \\ \mathrm{C} 4 & \text { clean ADAC-2A } \\ \mathrm{C}_{\mathrm{AF}} & \text { axial force coefficient, Fx } / \mathrm{q}_{\infty} \mathrm{S}_{\mathrm{ref}} \\ \mathrm{C}_{\mathrm{N}} & \text { normal force coefficient, } \mathrm{F}_{Z} / \mathrm{q}_{\infty} \mathrm{S}_{\text {ref }} \\ \left(\mathrm{C}_{\mathrm{N}}\right)_{\mathrm{C}} & \text { cumulative sectional normal force coefficient, } \mathrm{F}_{\mathrm{Z}} / \mathrm{q}_{\infty} \mathrm{S}_{\mathrm{ref}} \\ \mathrm{C}_{\mathrm{m}} & \text { pitching moment coefficient, pitching moment } / \mathrm{q}_{\infty} \mathrm{S}_{\mathrm{ref}} \mathrm{X}_{\mathrm{mrc}} \\ \mathrm{C}_{\mathrm{RM}} & \text { rolling moment coefficient, rolling moment } / \mathrm{q}_{\infty} \mathrm{S}_{\mathrm{ref}} \mathrm{Dia} \\ \mathrm{C}_{\mathrm{p}} & \text { pressure coefficient, p-p } \mathrm{p}_{\infty} / \mathrm{q}_{\infty} \\ \mathrm{CFD} & \text { computational fluid dynamics } \\ \text { CP } & \text { center of pressure } \\ \text { CPU } & \text { Central Processing Unit } \\ \text { DAC } & \text { Design Analysis Cycle }\end{array}$

* Research Engineer, Configuration Aerodynamic Branch, Associate Fellow AIAA 


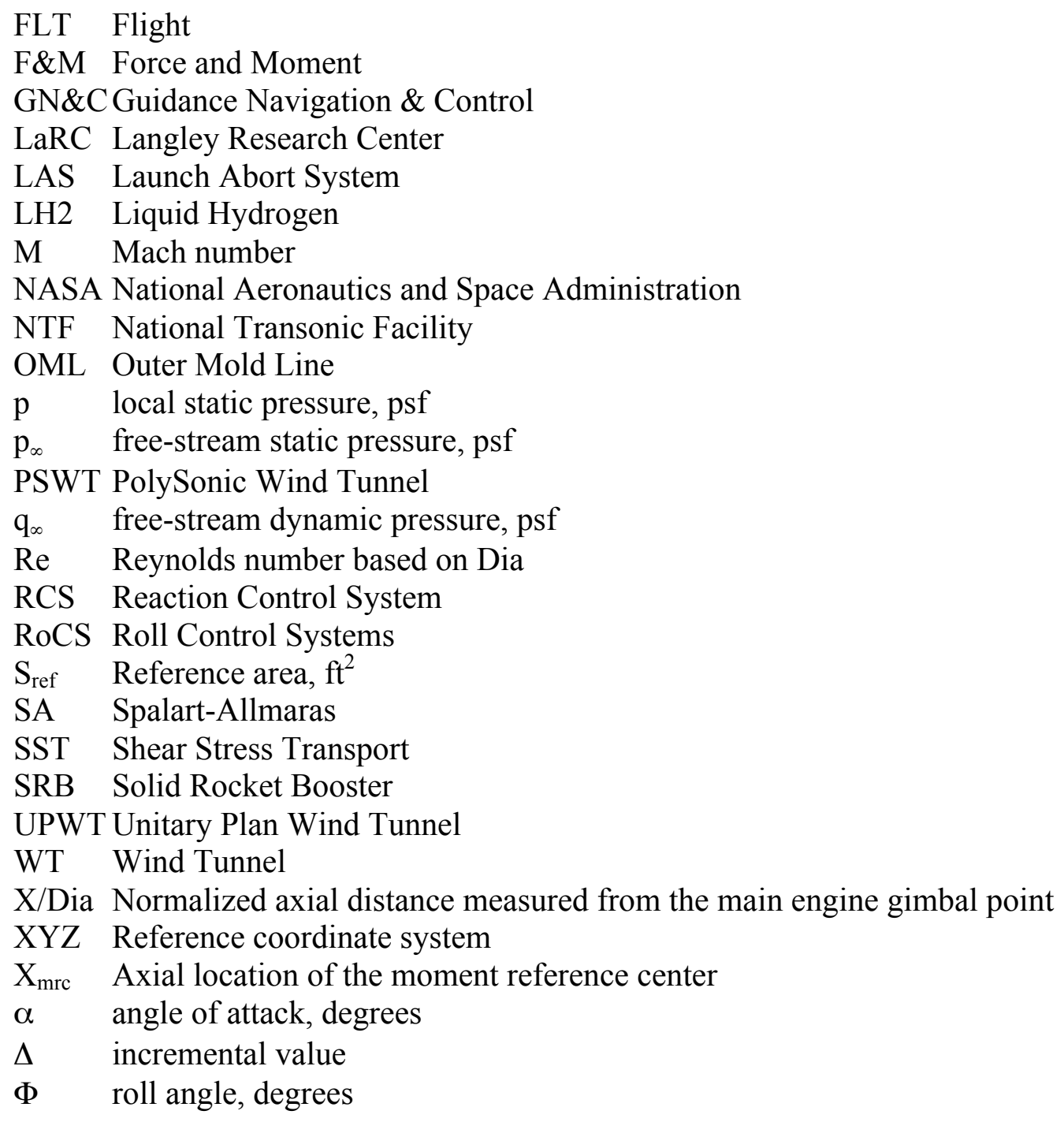

\section{Introduction}

NASA's Constellation program [1] was initiated to address the needs of U.S. access to space in the post space shuttle era with the mission to the moon, Mars and beyond. Unlike the space shuttle, where both crew and cargo are launched simultaneously, the architecture for the Constellation program proposed two separate launch vehicles: the Ares-I for the crew and the Ares V for the cargo. The Ares-I, the vehicle of interest in the present study, is a two-stage rocket that incorporates a modified five-segment solid rocket booster from the shuttle program while the upper stage is powered by the $\mathrm{J}-2 \mathrm{X}$ engine from the Apollo program. The major components of the vehicle and the proposed nominal flight trajectory are shown conceptually in Figure 1. The Ares-I major components consist of the Launch Abort System (LAS), Crew Exploration Vehicle (CEV) named Orion, the Upper Stage (US), and the First Stage (FS) Solid Rocket Booster (SRB) that includes the frustum, and the aft-skirt. 


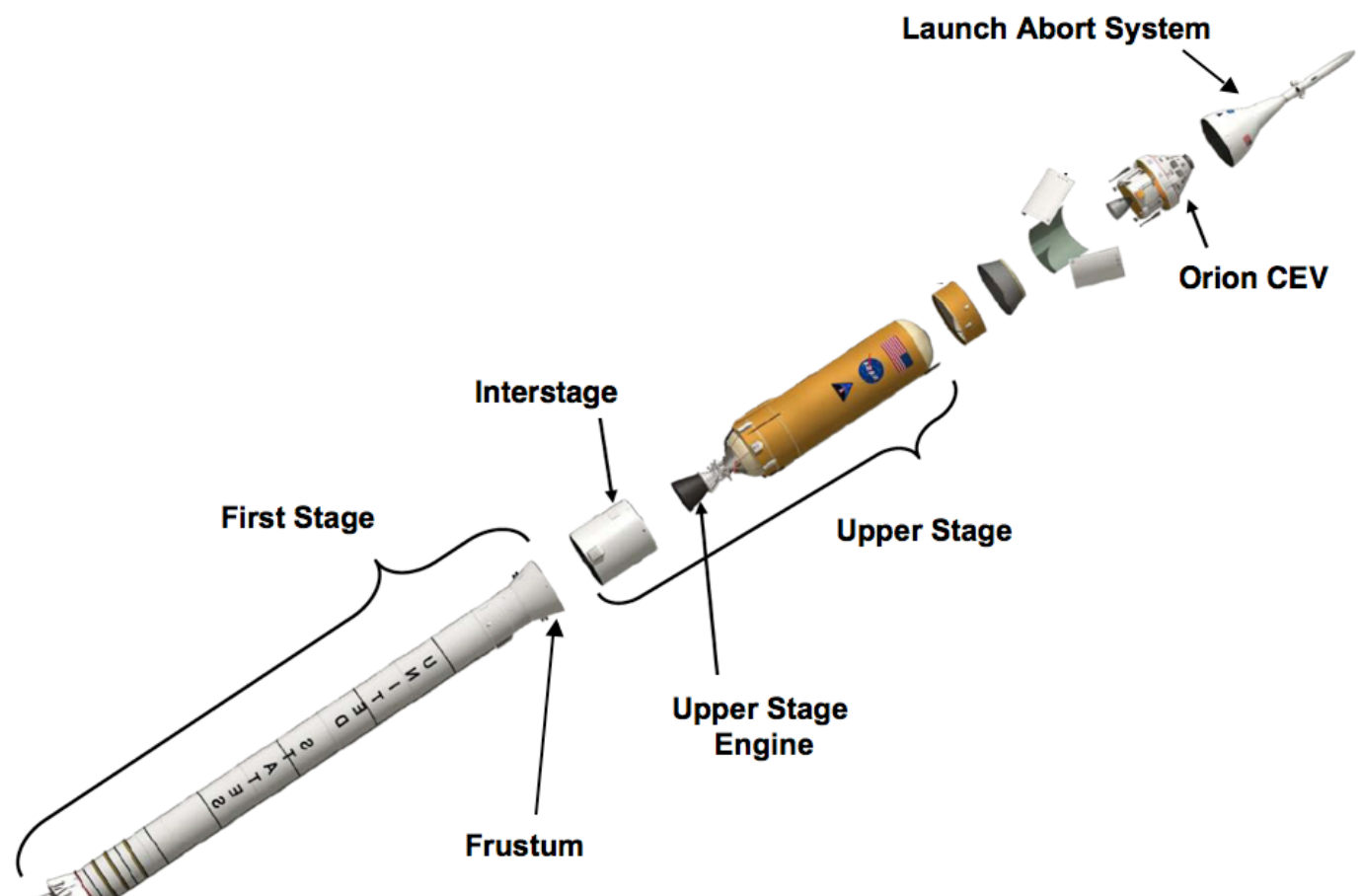

Aft-skirt

a)- Major components.

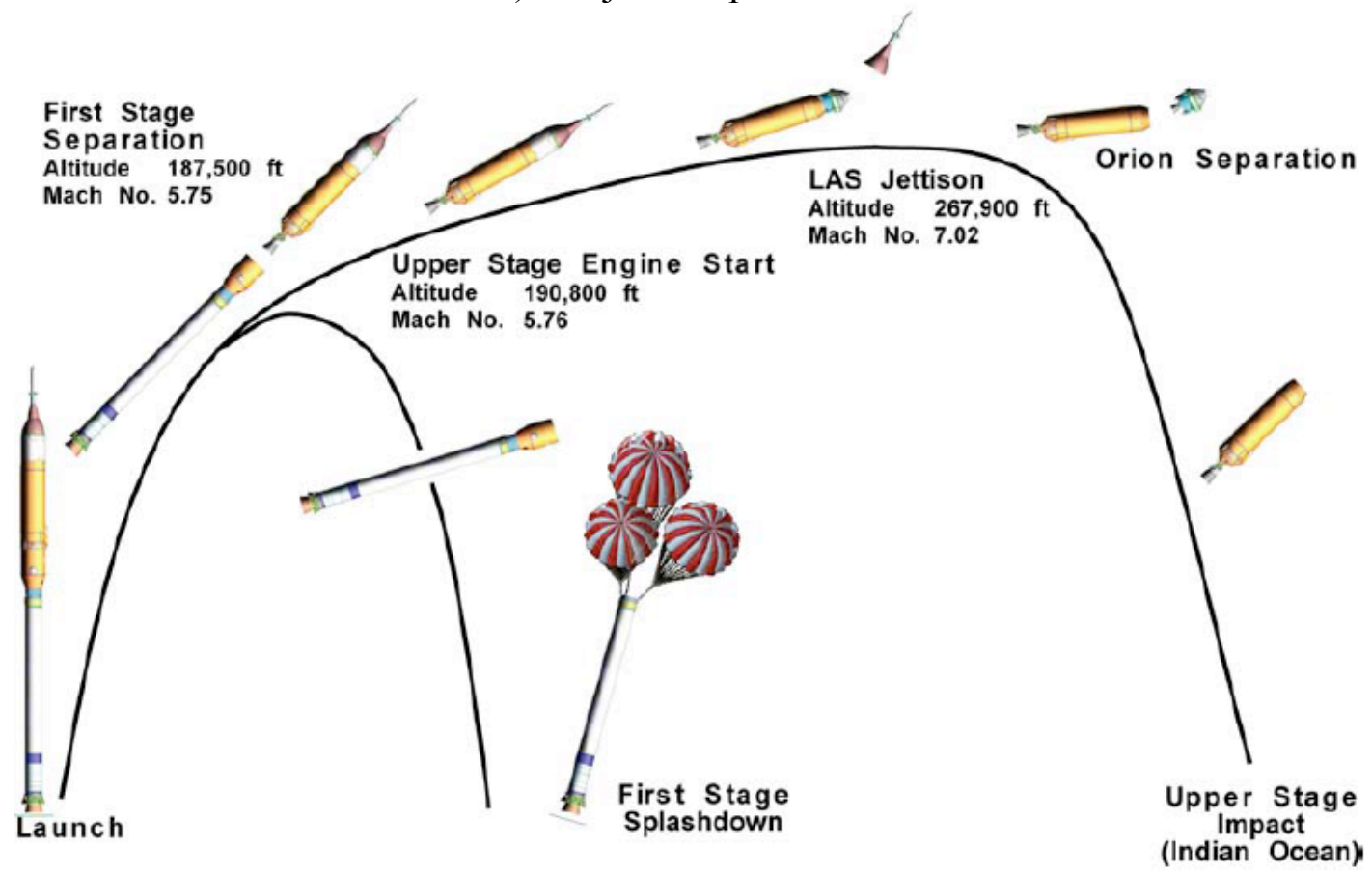

b)- Nominal flight trajectory [2].

Figure 1. Ares-I major components and its nominal flight trajectory. 
The Ares-I Design Analysis Cycle (ADAC) outer mold line (OML) definition has evolved in time, as shown in figure 2, with the progression of design refinements over the past few years. These design refinements are being incorporated to satisfy various discipline constraints such as the structural loads over the vehicle and on the individual protuberances, aerodynamic performance, flight guidance, navigation, and control (GN\&C), etc. There are numerous protuberances on the vehicle, adding to the complexity of the geometry and the resulting flow physics of the numerical simulation, as well as the wind tunnel model design, fabrication and testing. For example, figure 3 shows a translucent front view of a typical Ares-I vehicle and a list of individual and the group of protuberances along with the abbreviations used in the present analysis. Such protuberances included the LAS nozzles, CEV umbilical cover, many others over the US and the FS such as the Roll Control System (RoCS), Reaction Control System (RCS), Liquid Hydrogen (LH2) feed-line, Systems Tunnel, Booster Deceleration Motors (BDM), Booster Tumbling Motors (BTM), hold-down wedges, and many other smaller ones such as cameras, antennas, and rings.

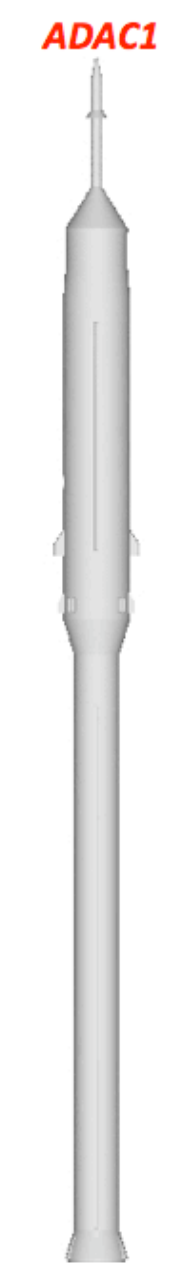

Early 2006

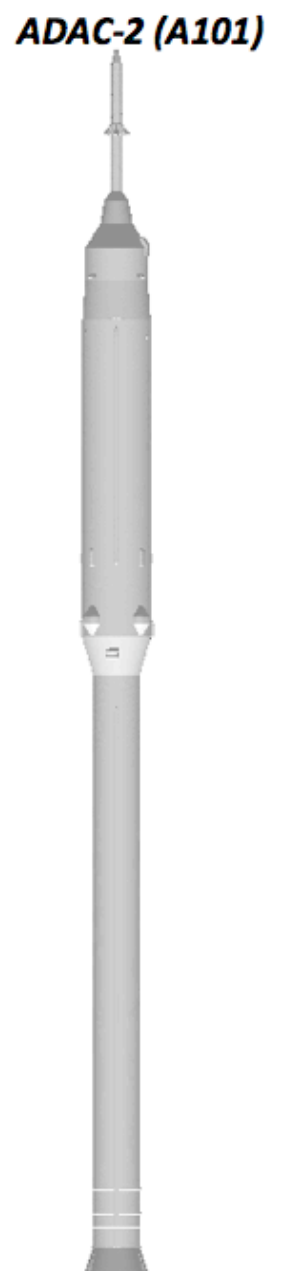

Early 2007
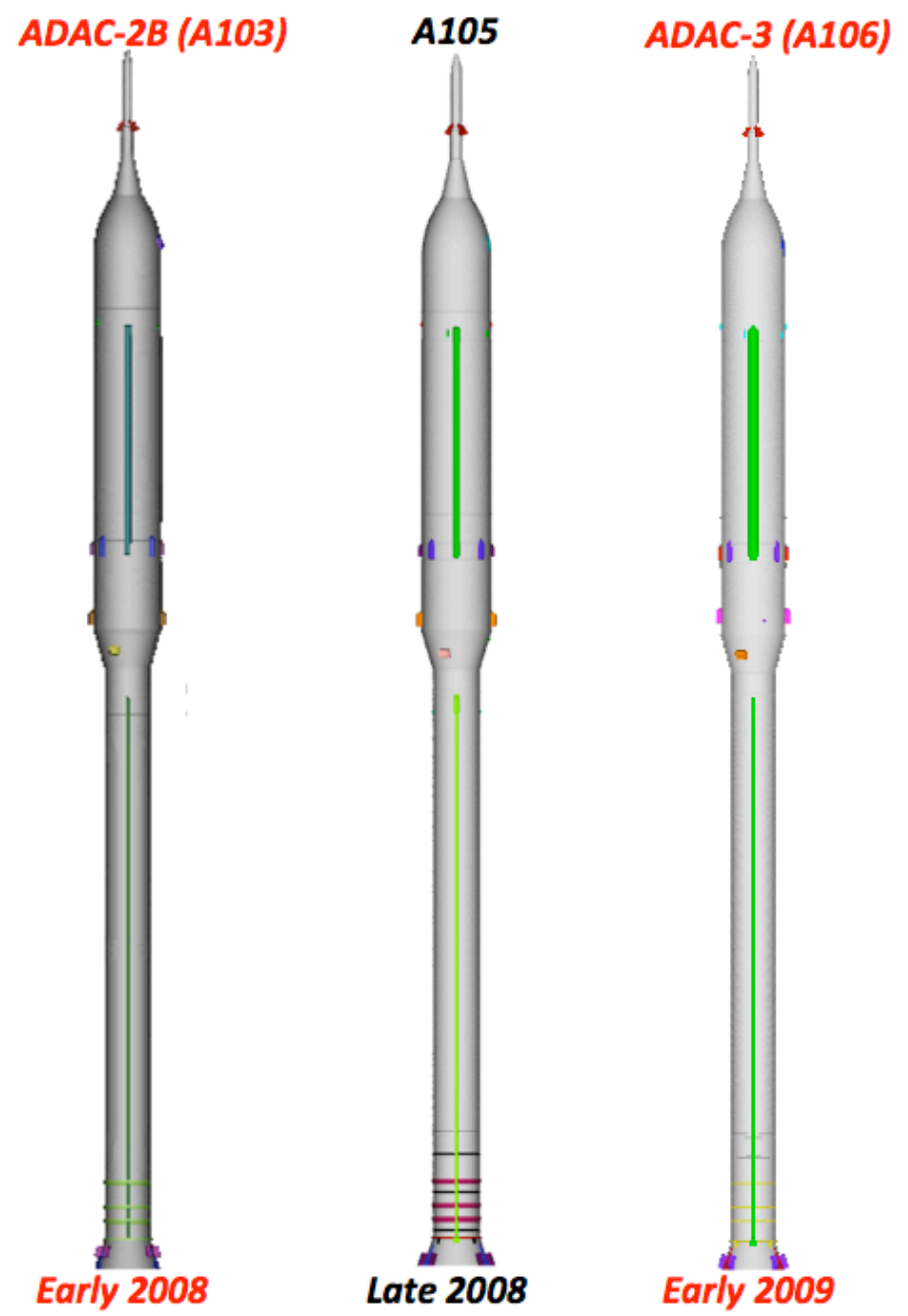

Figure 2. Evolving Ares-I configurations. 


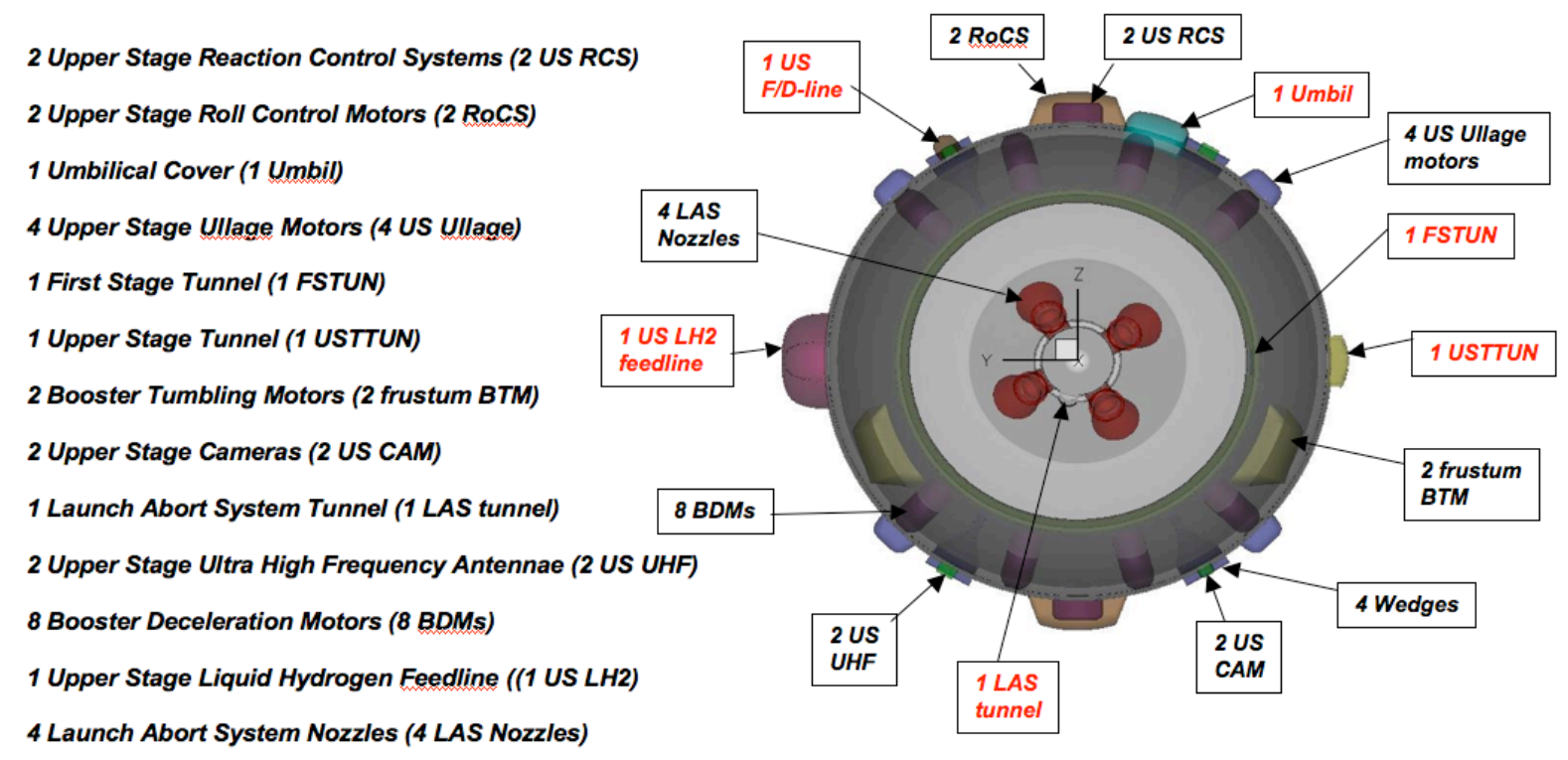

1 Upper Stage Fill/Drain-Line (1 US F/D-line)

4 Wedges

\section{Translucent Front View}

Figure 3. Typical Ares-I vehicle with protuberances.

Complementary to ground based wind tunnel and flight tests, Computational Fluid Dynamic (CFD) methods are being extensively used to aid the design and the ascent aerodynamic database development of the proposed crew launch vehicle. One such CFD method is the NASA's Langley Research Center (LaRC) developed Navier-Stokes flow solver USM3D [3] that has been designated to be the primary code to develop the necessary computational aerodynamic data within the Ares project. Two other widely used flow solvers, FUN3D [4] and OVERFLOW [5], have supporting roles to provide complementary results for fewer cases as part of a confidence building process to ensure code-to-code solution consistency. The initial data requirements from CFD was to provide the integrated longitudinal normal force distribution (i.e., sectional line-load) along the length of the vehicle for structural design and to provide an estimate of the Reynolds number (Re) effects increment from the sub-scale model testing in wind tunnels (WT) and full scale vehicle in flight (FLT). Such numerical data are very difficult to obtain experimentally, as it will be discussed later, at sub-scale model dimensions with all the protuberances attached. The nominal ascent flow conditions generally ranging over $0^{\circ}<\alpha<8^{\circ}$, $0.5<\mathrm{M}<4.5$, at various vehicle's roll angles $(\Phi)$ over 360 degrees. Currently, there is no ground facility to support testing at flight Reynolds number for the Ares-I class of vehicles.

At the inception of the Ares-I ascent aerodynamics project, an aerodynamic panel was formed [6] to provide the technical oversight over the data generation, results and analyses. The aerodynamic panel quickly became a venue for technical exchange of information between the experimental, CFD, and the management teams. This interaction fostered an expanded role for various technical groups and disciplines, and in particular the CFD team as shown in the diagram in figure 4. In addition to the initial two data requirements (i.e., sectional line-load and the WTto-FLT Re incremental effects), the CFD data were used by various other elements of the project 
such as the venting and debris analysis groups, and the load analysis teams for the Orion capsule and individual protuberances. Also, the availability of the CFD data prior to the start of wind tunnel testing was found useful in aiding the model design, protuberance fabrications, test matrix development, and instrumentation distribution in the regions of interest where major flow changes were occurring. Furthermore, the CFD data were utilized in a number of trade studies to address the first order aerodynamic effects from changes made to various protuberances such as geometrical modifications, repositioning, and/or the addition of a proposed new one to improve the vehicle's performance. Examples of such trade studies included the height variations of the upper stage system tunnel and LH2 feed-line; and/or replacing of the upper stage pressure tunnel with the system tunnel, etc. Complementary to the experimental data, all the CFD results were also made available to the appropriate ascent aerodynamic database development team [7] as well as the uncertainty quantification group [8]. Although, the GN\&C aerodynamic database was primarily developed from the wind tunnel data due to their consistency in acquiring large amount of data points in a timely manner, the available CFD results were used as a sanity check to anchor the measurements. In particular, the CFD results were found to be necessary for the extrapolation of the sub-scale wind tunnel data to flight Reynolds number, although such a practice has not been validated for the Ares-type vehicles. However, a limited set of high Re wind tunnel data, which reached to approximately one tenth of the appropriate flight level, were obtained from the Langley's National Transonic Facility (NTF) at transonic speeds to aid anchoring the slope of the extrapolation curve at the lower end. Sample results that show a comparison between the computed and measured surface pressure coefficients for the ADAC-2B (A103) at transonic speed for the high Re will be discussed later.

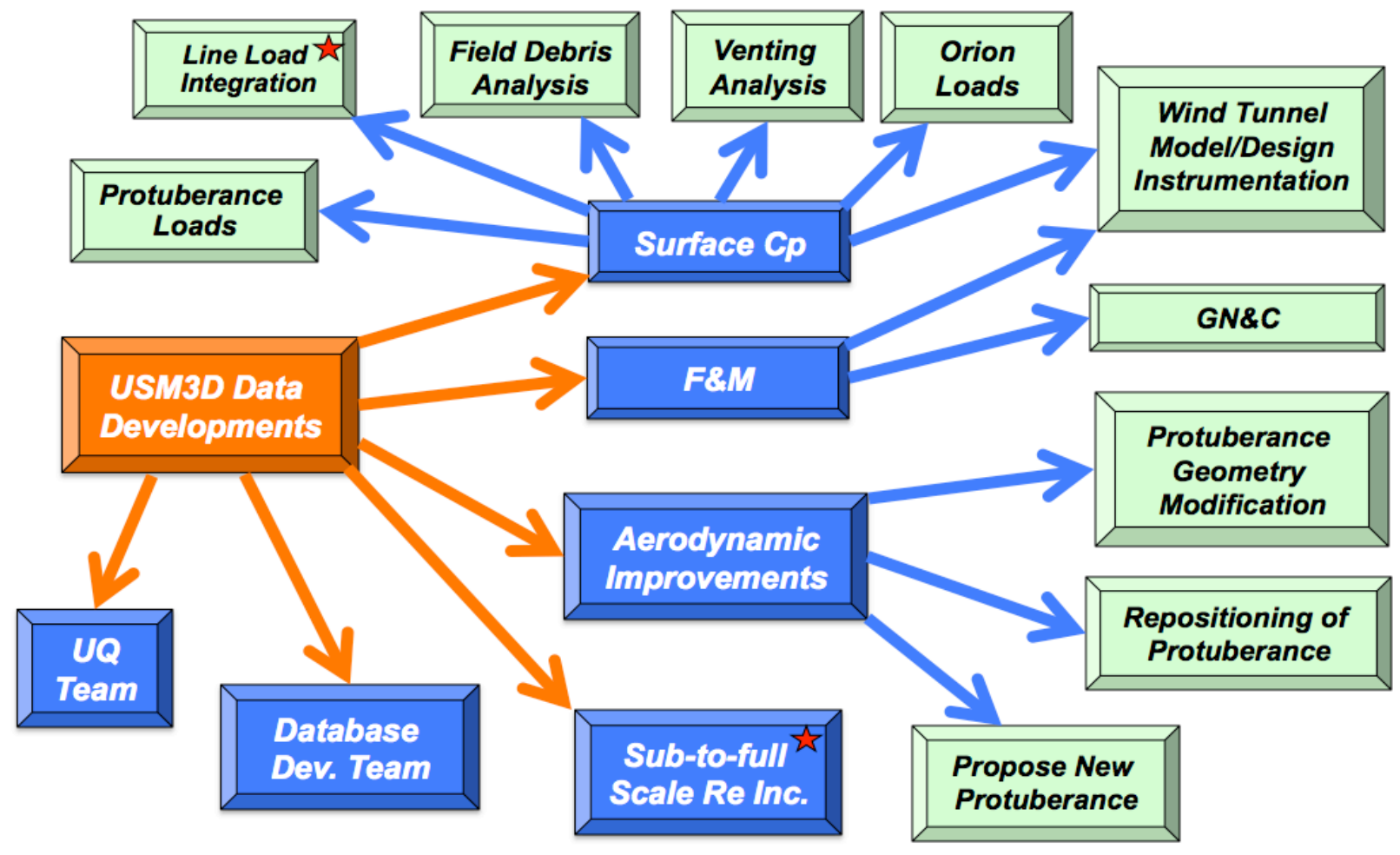

Data difficult to obtain, if not practical, any other way than CFD.

Figure 4. USM3D data development and applications in Ares-I project. 
The objective of the present study is to provide an overview of the computational activities conducted at LaRC in support of the external flow aerodynamic analysis, without any propulsion effects, of the evolving the Ares-I vehicle at nominal ascent flow conditions up to the first stage separation (See figure 1b). The emphasis will be placed on the correlations of CFD results with the available experimental data for selected configurations. This CFD paper complements two other aerodynamic overview reports with the focus on the Ares-I project from the aerodynamic panel perspective [6] and the experimental investigations [9]. Computational results are based on the three dimensional, Reynolds-averaged Navier-Stokes equations with the assumption that the flow is fully turbulent over the entire vehicle. In addition, efforts have been made to build upon these analyses by incorporating some power-on effects, in particular for the RoCS thrusters, using the same CFD methodology and code-to-code verification support from the OVERFLOW and Loci-Chem flow solvers [10 and 11]. Finally, the recent enhancements to the flow solver that facilitated such applications within Constellation program will be reported by Pandya et. al. [12].

\section{USM3D Flow Solver}

\section{Computational Approach}

USM3D [3] is a tetrahedral cell-centered, finite volume, Euler and Navier-Stokes flow solver. Time integration follows the implicit point Gauss-Seidel algorithm, explicit Runge-Kutta, and local time stepping for convergence acceleration. The solver scheme allows various options for computing the inviscid flux quantities across each cell face. These include Roe's fluxdifference splitting (FDS), advection upstream splitting method (AUSM), flux vector splitting (FVS), and Harten, Lax, and van Leer with contact restoration (HLLC) scheme. MinMod and Superbee flux limiters have been incorporated in the flow solver to smooth out the flow discontinuities due to shock waves. Turbulence models include Spalart-Allmaras (SA) [13] with and without wall function, k- $\varepsilon$ [14], Shear Stress Transport (SST) [15], and algebraic stress models. In addition to standard slip/no-flow through (inviscid surface) and no-slip/no-flow through (viscous surface) boundary conditions, the method also includes a transpiration boundary condition that can be used to simulate propulsion effects. Although USM3D is used mainly for ideal gas simulation with constant $\gamma$, options for variable $\gamma$ and limited real gas effects are also available in the code.

\section{Grid Generation}

The surface triangulations along with field tetrahedral volume grids were generated using the GRIDTOOL [16] and VGRID [17] software developed at LaRC. A rectangular box enclosing the vehicle is typically used to define the computational domain far-field boundaries. Each face of this rectangular box is located approximately several body lengths away from the configuration in the upstream, transverse, and downstream direction. The normal spacing of the first cell height above the vehicle surface is about 0.01 inches, in full-scale dimension, for the WT Re grid. Same surface grid definition is also used to generate the corresponding volume grid for the flight $\mathrm{Re}$ with a much smaller height for the first cell normal spacing to resolve the expected thinner boundary layer. As a result, the finer grid resolved boundary layer for the flight Re cases generally contained about $20 \%$ more volume cells than its counterpart grid designed for the 
computations at wind tunnel Re. All computational grids used in the present analysis included a sting geometry representation of the WT model.

\section{Solution development, convergence, verification and validation}

Many efforts were made early on during the course of this activity to establish the appropriate parameter settings for the USM3D flow solver, such as the flux schemes, limiters and turbulence model to ensure the solution development remains stable over the nominal ascent range of the flow conditions [18, 19, 20 and 21]. This led to the development of an efficient script that would automatically generate appropriate input-stream parameters to the flow solver and submit series of cases such as a Mach or angle-of-attack sweep to a designated computer platform. Upon completion, a summary page pertinent to the solution convergence characteristics would be generated for quality assurance purposes. A typical summary page for the ADAC-3 (A106) configuration is shown in figure 5. This summary page includes the designed statistical convergence data for the longitudinal and lateral aerodynamic force and moment characteristics as well as the flow solution residuals and the final surface flow property. It should be noted that all present computations have been performed at the NASA's Advanced Supercomputer (NAS) complex located at the Ames Research Center.
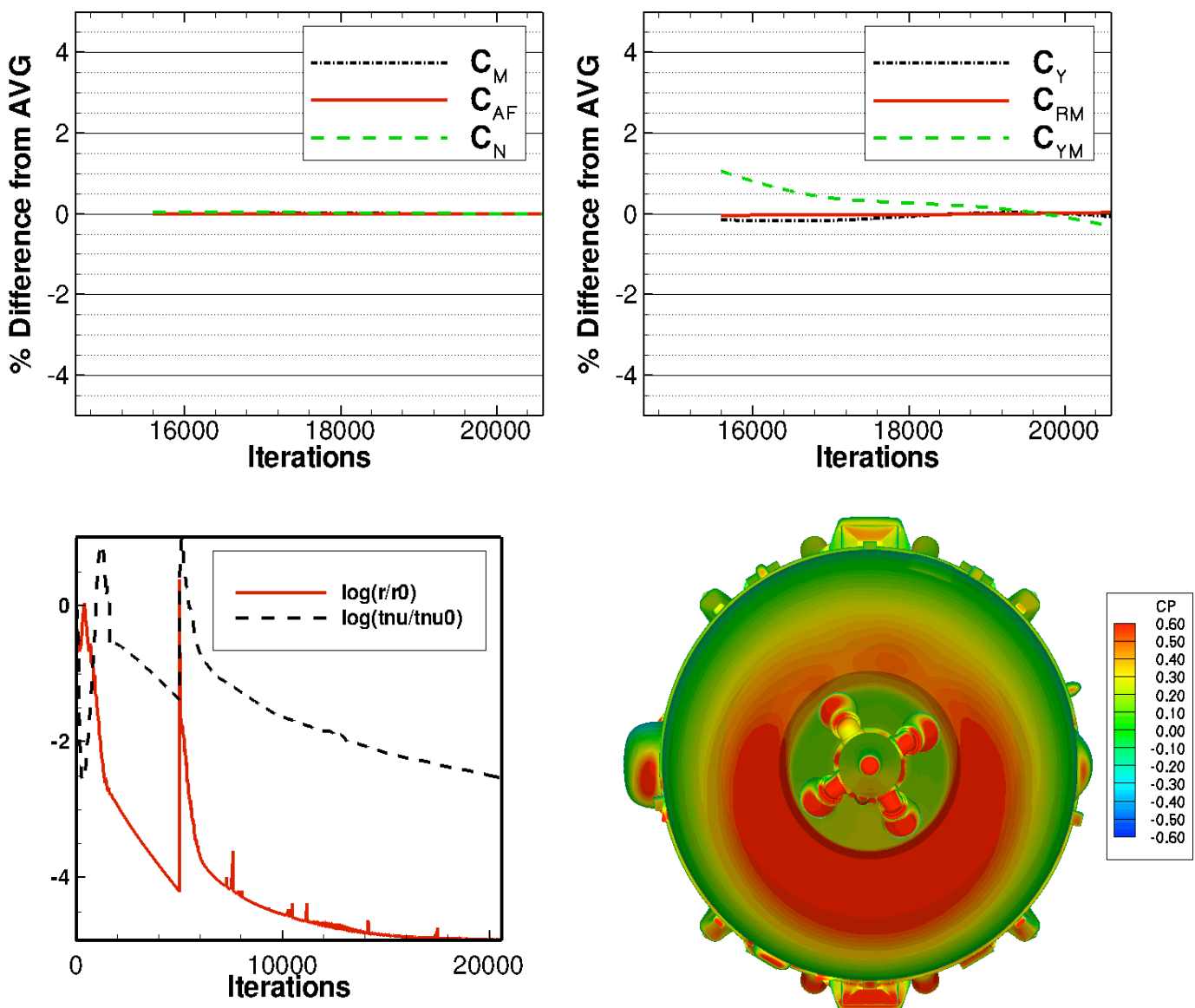

Figure 5. Typical solution convergence for the ADAC-3 (A106), $M=1.6, \alpha=8^{0}, \Phi=0^{0}$, FLT Re. 
Solution convergence is evaluated by monitoring the overall fluctuations in all six longitudinal and lateral aerodynamic coefficients, in particular the longitudinal aerodynamic coefficients $\left(\mathrm{C}_{\mathrm{N}}, \mathrm{C}_{\mathrm{AF}}, \mathrm{C}_{\mathrm{m}}\right)$ and the vehicle total rolling moment coefficient $\left(\mathrm{C}_{\mathrm{RM}}\right)$. A solution is considered converged when the fluctuations in the 4-component coefficients $\left(\mathrm{C}_{\mathrm{N}}, \mathrm{C}_{\mathrm{AF}}, \mathrm{C}_{\mathrm{m}}\right.$, and $\mathrm{C}_{\mathrm{RM}}$ ) become generally less than $0.5 \%$ of its average final value over the last 2000 iterations along with about 2-5 orders of magnitude drop in the solution residuals for density (i.e., $\log (\mathrm{r} / \mathrm{r} 0))$ and turbulent viscosity (i.e., $\log (\operatorname{tnu} / \mathrm{tnu} 0))$. In addition to this summary page, a series of post processing are performed on a given solution to generate data in various forms and formats useful for the project needs.

A conventional approach, that has been refined over the course of this activity, is used for the verification and validation of the predicted numerical results at wind tunnel Re. This approach is shown in the diagram in figure 6. Within the Ares project, the verification of the computational results is viewed as the ability to demonstrate the correctness of the mathematical understanding of the underlying flow physics associated with such class of vehicles over the nominal ascent range of flow conditions. Whereas, the validation of the computational results is primarily based on how well the numerical predictions compared to the real-world experimental data.

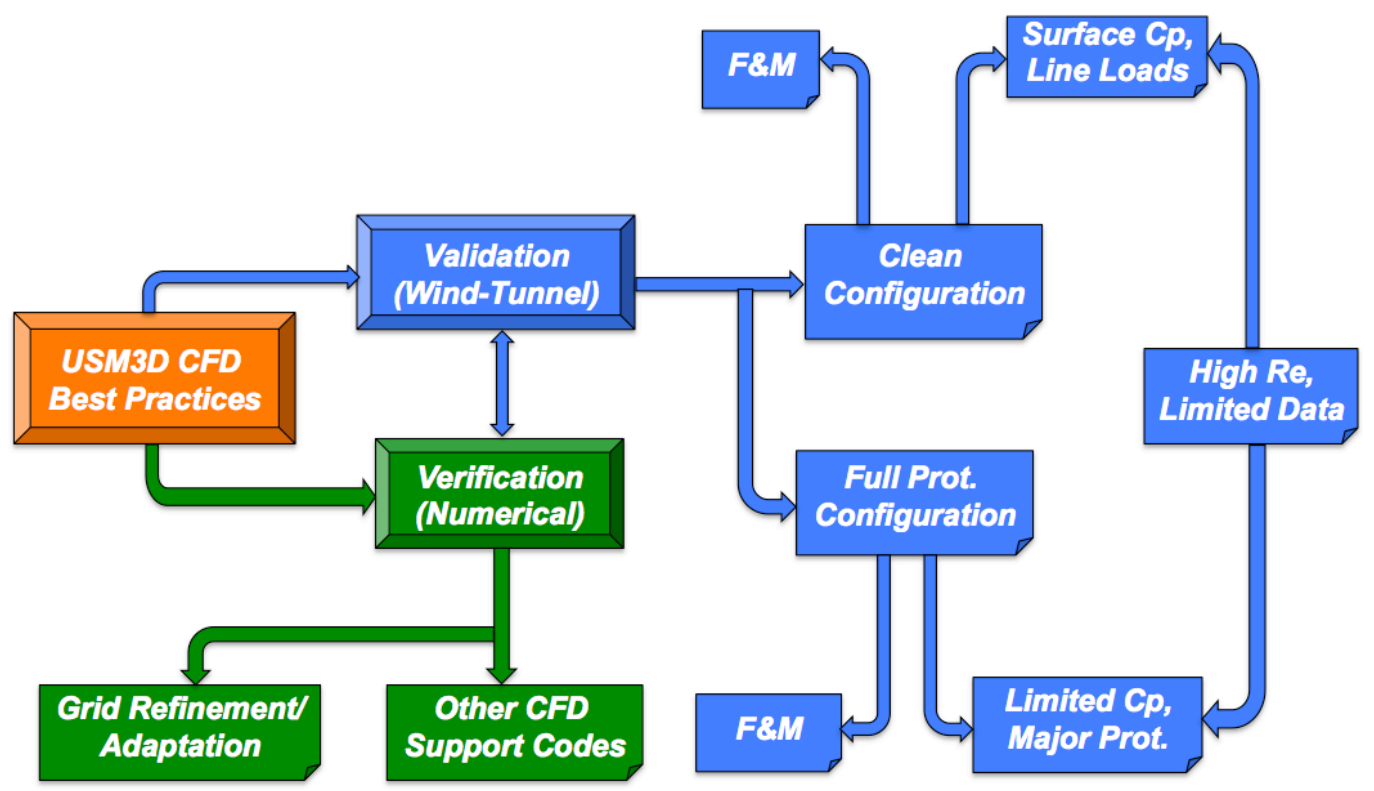

Figure 6. Verification and validation approach used for USM3D results.

The verification process in the present activity is accomplished by comparing the numerical results that has been obtained from other Navier-Stokes based CFD flow solvers to ensure codeto-code solution consistency. Some representative comparison between the results from USM3D and OVERFLOW as well as FUN3D will be shown later. As part of this verification process, efforts were made to address the sensitivity of the computed results to various factors such as grid refinement/adaptation, turbulence models, flux schemes and limiters. Some representative results from such sensitivity studies will also be shown later.

The validation process of the computational results is primarily made through comparisons with the available experimental data such as the surface $\mathrm{Cp}$, the total force and moment coefficients, and the integrated longitudinal normal force coefficients. The validation effort was 
conducted for two variations of the configuration; the clean vehicle and the vehicle configured with full protuberances. In addition to the total force and moment measurements, the clean configuration is primarily used to measure the surface $\mathrm{Cp}$ with sufficient density to facilitate accurate sectional line-load integration to validate the corresponding numerical predictions. A technique, developed by Samareh [22], was used to compute the sectional line-loads based on the circumferential integration of the surface pressure coefficients over small longitudinal slices of the vehicle. The computed sectional line-loads for the configuration with full protuberances can not be validated because it is difficult, or impractical, to instrument a sub-scale wind tunnel model of this size (i.e., typically a $1 \%$ to $2 \%$ of full scale vehicle) with a large number of pressure ports that are required for an accurate integration of the sectional line-loads. However, as it will be discussed later, limited surface $\mathrm{Cp}$ measurements have been obtained on the configuration with full protuberances at selected locations and are used towards a partial validation of the computational results but not for the line-loads. As a result, only the total force and moment coefficients measured on the model with full protuberances are used to validate the numerical predictions. Furthermore, a limited set of surface pressure data has also been obtained in the $0.5<\mathrm{M}<1.1$ range at high $\mathrm{Re}$, for both the clean and the full protuberances configurations in the NTF for CFD solution validation purposes. Sample measured data at high Re and the correlation with the computational results will be discussed later.

\section{Results and Analyses}

\section{$\underline{\mathrm{ADAC1}}$}

In the early 2006, the released OML definition of the ADAC1 configuration was used to extract the appropriate geometry description of the vehicle in IGES format. The IGES file was used to define the computational surface grid with different density, leading to the subsequent volume grid generation, and grid refinement study for the clean configuration. As part of the solution sensitivity to grid refinement study, four sets of grids with various densities were generated and the statistics, in terms of total number of cells in the computational domain and surface triangles, are shown in table 1 . These grids were used to compute the flow at nominal ascent flow conditions using both the SA and the SST turbulence models.

Table 1. Surface and volume grid statistics for the ADAC1 configuration.

\begin{tabular}{|c|c|c|c|c|c|c|c|}
\hline \multicolumn{2}{|c|}{ Coarse Grid (CG) } & \multicolumn{2}{c|}{ Base Grid (BG) } & \multicolumn{2}{c|}{ Fine Grid (FG) } & \multicolumn{2}{c|}{ Super Fine Grid (SFG) } \\
\hline $\begin{array}{c}\text { Volume } \\
\text { Cells }\end{array}$ & $\begin{array}{c}\text { Surface } \\
\text { triangles }\end{array}$ & $\begin{array}{c}\text { Volume } \\
\text { Cells }\end{array}$ & $\begin{array}{c}\text { Surface } \\
\text { triangles }\end{array}$ & $\begin{array}{c}\text { Volume } \\
\text { Cells }\end{array}$ & $\begin{array}{c}\text { Surface } \\
\text { triangles }\end{array}$ & $\begin{array}{c}\text { Volume } \\
\text { Cells }\end{array}$ & $\begin{array}{c}\text { Surface } \\
\text { triangles }\end{array}$ \\
\hline$\sim 3 \times 10^{6}$ & $\sim 28,000$ & $\sim 5 \times 10^{6}$ & $\sim 50,000$ & $\sim 10 \times 10^{6}$ & $\sim 90,000$ & $\sim 19 \times 10^{6}$ & $\sim 150,000$ \\
\hline
\end{tabular}

The effects of turbulence model on computed $\mathrm{C}_{\mathrm{AF}}$ and $\mathrm{C}_{\mathrm{N}}$ are shown in figure 7 for the base and super fine grids as a function of Mach number at $\alpha=7^{\circ}$, WT Re. The figure also includes the corresponding measured data obtained from the Langley's Unitary Plan Wind Tunnel (UPWT) [23] and the Boeing PolySonic Wind Tunnel (PSWT) [24]. In general, the effect of grid refinement on the predicted $\mathrm{C}_{\mathrm{AF}}$ is shown to be small across the examined Mach range. Also, the results indicate that the effect of turbulence model on the computed $\mathrm{C}_{\mathrm{AF}}$ is relatively larger at 
low supersonic and especially at low subsonic Mach number of 0.5 . The effects of both turbulence model and the grid refinement appear to produce nearly a constant shift in the computed $\mathrm{C}_{\mathrm{N}}$ for the entire Mach range, except at $\mathrm{M}=0.5$. With a given grid size, the SST model generally predict a higher $\mathrm{C}_{\mathrm{N}}$ compared to the SA model. However, with a given turbulence model, the computed $\mathrm{C}_{\mathrm{N}}$ decreases with grid refinement. In general, the measured data tend to fall within the scatter of the computational results associated with different turbulence models and various grid densities, and that the correlation between experimental and computational data is fairly good over the examined Mach number range. However, the solution development with the SA turbulence model was found to be generally more stable, robust and efficient relative to the SST model. Further discussion on the results and the effects from such studies of the grid refinement and turbulence models can be found in references 18 and 25 .
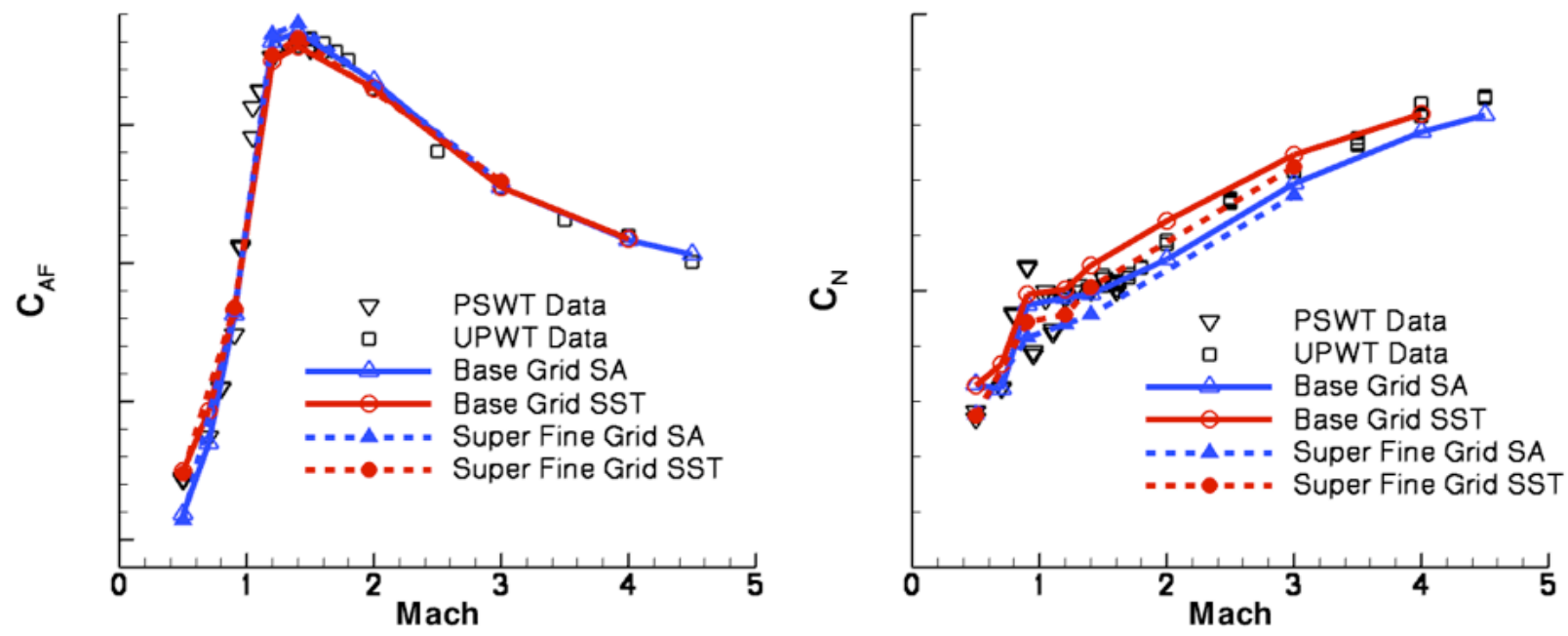

Figure 7. Computed effects from different turbulence model and grid refinement, and comparison with measured $\mathrm{C}_{\mathrm{AF}}$ and $\mathrm{C}_{\mathrm{N}}$ for the clean ADAC1 configuration $\alpha=7^{0}$, WT Re.

Sample plots of the computed and measured sectional line-load [25] for two regions of the clean ADAC1 configuration are shown in figure 8 , for $\mathrm{M}=1.4, \alpha=7^{\circ}$, WT Re. The figure also shows the computed line-loads obtained from OVERFLOW and FUN3D that were generated as part of the code-to-code verification analysis. All computed results are based on the SA turbulence model and have been generated independently following a generally accepted approach for best practices associated with each method. In general, the computed line loads correlate reasonably well with one another as well as the measured WT data both in terms of overall trends and magnitudes. It should be noted that, with the proposed Ares-I trajectory, it is estimates that the maximum dynamic pressure would occur over the speed range of $1.2<\mathrm{M}<$ 1.8. As a result, special emphasis has always been placed in the aerodynamic performance analysis of various OML's over this speed range and in particular at $\mathrm{M}=1.6$. 

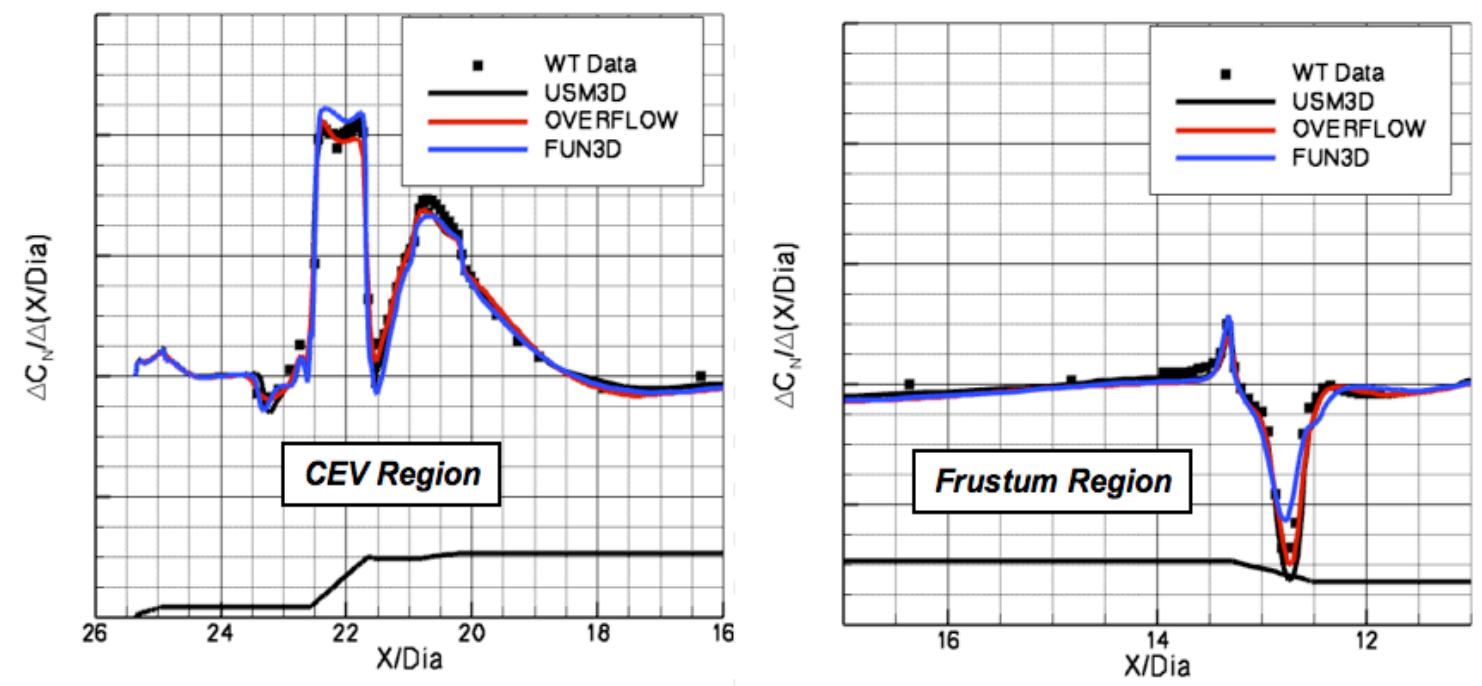

Figure 8. Computed and measured sectional line-load for the clean ADAC1 configuration, $\mathrm{M}=1.4, \alpha=7^{0}$, WT Re.

\section{$\underline{\operatorname{ADAC}-2 A(A 101)}$}

In the early 2007, the OML definition for the ADAC-2A (A101) configuration was released. A sample of the CFD results obtained at nominal ascent flow conditions for the ADAC-2A (A101) configuration [19] are presented in this section. Three geometric variations of the vehicle were modeled, as shown in figure 9, and they include the clean (ADAC-2A_C, also referred to as C4), simplified protuberances (ADAC-2A_SP, also referred to as C2) and the full protuberances (ADAC-2A_FP, also referred to as $\mathrm{C} 1$ ). Relative to the $\mathrm{C} 4$, the $\mathrm{C} 2$ configuration only incorporated the LAS nozzles and the umbilical cover geometries. Four sets of grids were generated for these geometries. The grid size statistics in terms of total number of cells in the computational domain and surface triangles are shown in table 2 . The computational grids ranged from $\sim 8 \times 10^{6}$ cells for the $\mathrm{C} 4$ at WT Re to $\sim 43 \times 10^{6}$ cells for the $\mathrm{C} 1$ configuration at FLT Re. Computations were performed at both WT and FLT Re for Mach numbers ranging from 0.5 to 4.0, at angles of attack of $0^{\circ}, 4^{\circ}$, and $7^{\circ}$. In addition, the $\mathrm{C} 2$ configuration was used in a separate study to assess the viability of an existing grid adaptation technique for possible improvements in either the solution development or aerodynamic prediction accuracy. The results from this study led to no significant improvements, particularly for a milestone/time driven project environment, and thus were not pursued any further.

Table 2. Surface and volume grid statistics for the ADAC-2A configuration.

\begin{tabular}{|c|c|c|c|c|c|c|c|}
\hline \multicolumn{2}{|c|}{ C4 (WT Re) } & \multicolumn{2}{c|}{ C2 (WT Re) } & \multicolumn{2}{c|}{ C1 (WT Re) } & \multicolumn{2}{c|}{ C1 (FLT Re) } \\
\hline $\begin{array}{c}\text { Volume } \\
\text { Cells }\end{array}$ & $\begin{array}{c}\text { Surface } \\
\text { triangles }\end{array}$ & $\begin{array}{c}\text { Volume } \\
\text { Cells }\end{array}$ & $\begin{array}{c}\text { Surface } \\
\text { triangles }\end{array}$ & $\begin{array}{c}\text { Volume } \\
\text { Cells }\end{array}$ & $\begin{array}{c}\text { Surface } \\
\text { triangles }\end{array}$ & $\begin{array}{c}\text { Volume } \\
\text { Cells }\end{array}$ & $\begin{array}{c}\text { Surface } \\
\text { triangles }\end{array}$ \\
\hline$\sim 8 \times 10^{6}$ & $\sim 220,000$ & $\sim 21 \times 10^{6}$ & $\sim 240,000$ & $\sim 26 \times 10^{6}$ & $\sim 350,000$ & $\sim 44 \times 10^{6}$ & $\sim 350,000$ \\
\hline
\end{tabular}




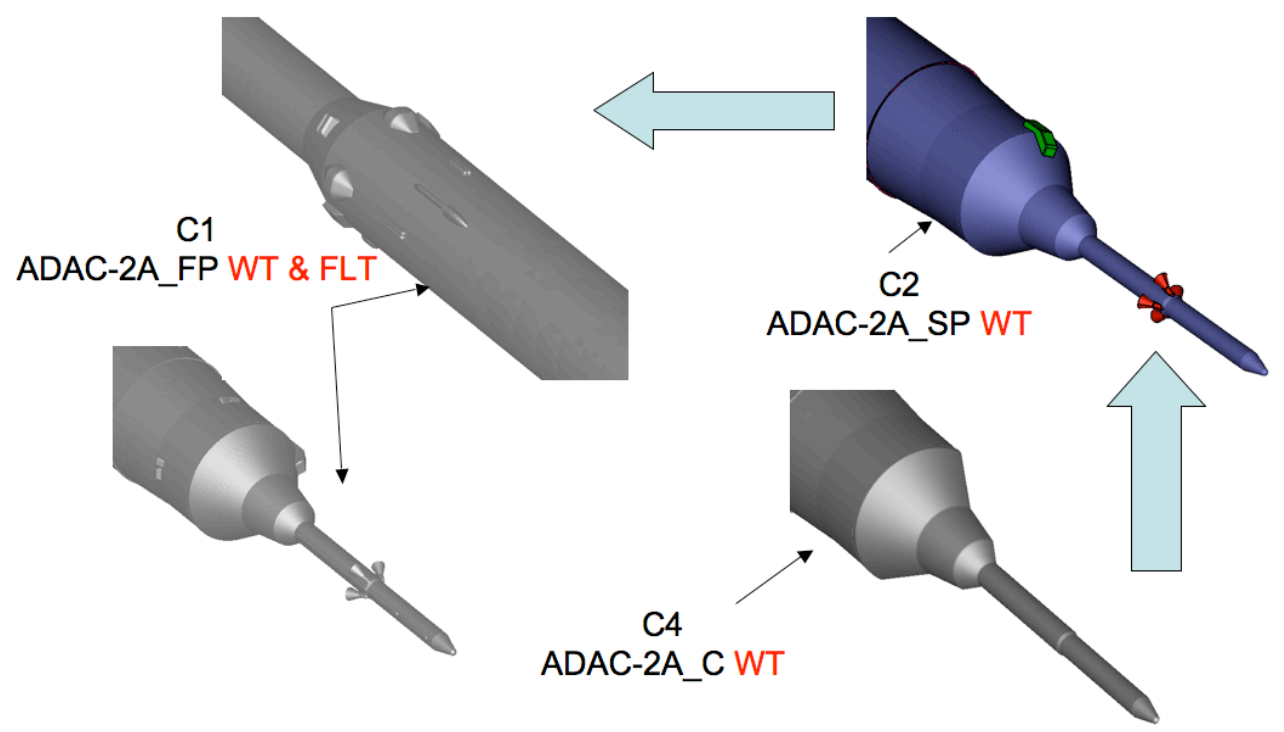

Figure 9. USM3D modeled geometry variations of the ADAC-2A (A101) configuration.

The computed and measured [23 and 24] $\mathrm{C}_{\mathrm{AF}}$ and $\mathrm{C}_{\mathrm{N}}$ for the $\mathrm{C}$ 1 configuration are shown in figure 10 as a function of Mach number at $\alpha=7^{\circ}$, WT Re. The figure also presents the same computed coefficients obtained from OVERFLOW and FUN3D that were generated as part of the code-to-code verification process. The computed $\mathrm{C}_{\mathrm{AF}}$ values from all three flow-solvers agree reasonably well with one another, and slightly under-estimate the measured axial force coefficient particularly over the low to mid-supersonic speed range. The measured $\mathrm{C}_{\mathrm{N}}$ values generally fall within the scatter of the computational results obtained from different flow solvers over the examined Mach range. The computed results for both coefficients clearly capture the overall characteristics of the measured data.
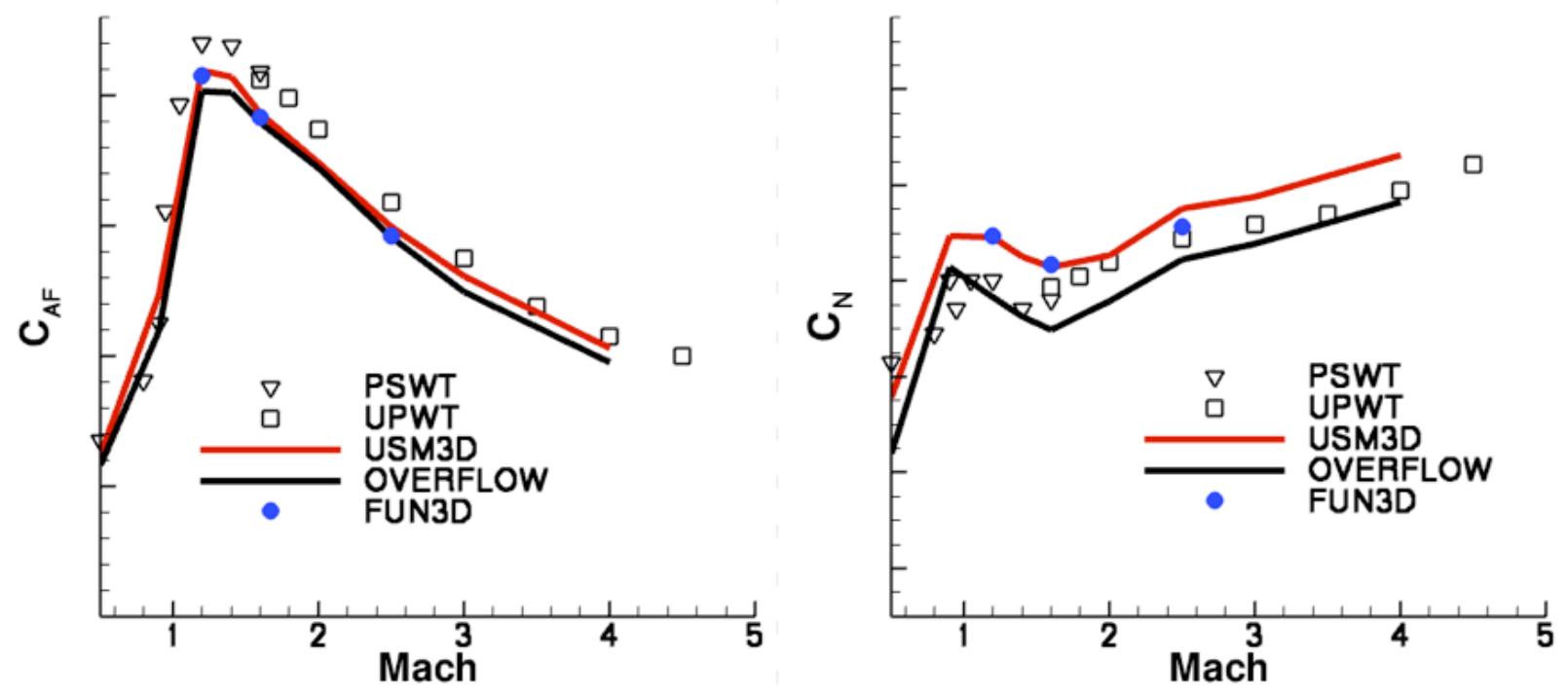

Figure 10. Computed and measured $C_{A F}$ and $C_{N}$ for the ADAC-2A (A101) with full protuberances (C1), $\alpha=7^{\circ}$, WT Re. 
An effort was initiated during the course ADAC-2A (A101) computational analysis in establishing the required procedure to isolate the contribution of each protuberance towards the vehicle's total integrated aerodynamic forces and moments. A sample result from this activity that shows the $\mathrm{C}_{\mathrm{AF}}$ contribution, as a fraction of the vehicle's total, from individual or a group of protuberances is presented in figure 11 for various Mach number at $\alpha=7^{\circ}$, and WT Re. For example, the computed results indicate that the majority of the $\mathrm{C}_{\mathrm{AF}}$ contributions from the protuberances are coming from the BDM's, the stiffeners/kick rings, and the LAS nozzles. Also, the maximum $\mathrm{C}_{\mathrm{AF}}$ contribution from the BDM's occur at $\mathrm{M}=0.9$ followed by a decreasing trends with increasing speed. Similar analysis has also been performed for all other computed coefficients. Such a data analysis was found useful in aiding the vehicle's protuberances design from an aerodynamic performance perspective. In particular, the contribution of various protuberances to the vehicle's rolling moment was found to be very important and a sample results will be shown later.

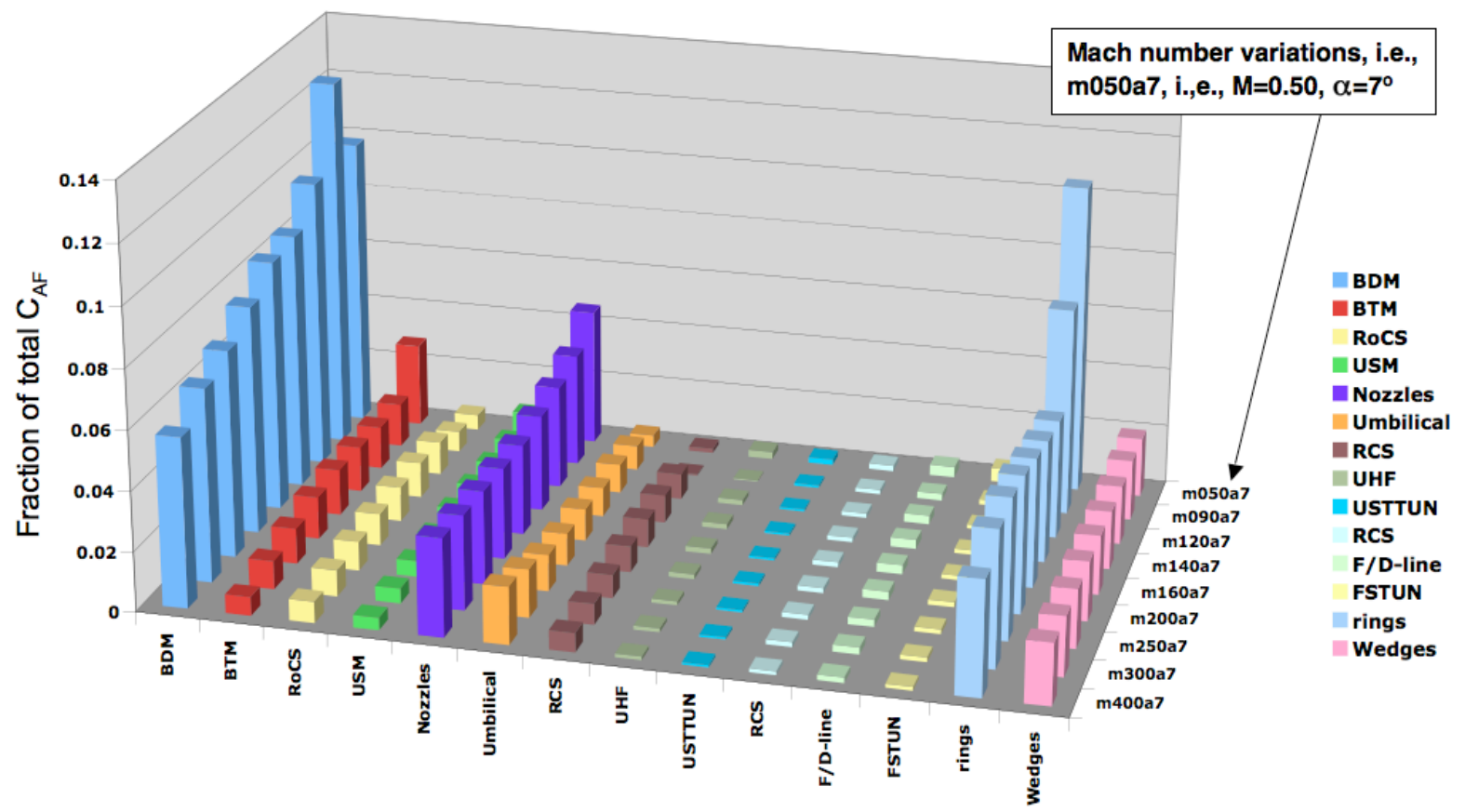

Figure 11. Individual/group protuberance(s) contribution to the computed $\mathrm{C}_{\mathrm{AF}}$ for the ADAC-2A (A101) C1 configuration, $\alpha=7^{0}$, WT Re.

The effects of protuberances and Reynolds number on the vehicle's cumulative normal force coefficient $\left(\mathrm{C}_{\mathrm{N}}\right)_{\mathrm{C}}$, computed at $\mathrm{M}=1.6, \alpha=7^{\circ}$, are shown in figure 12 . The results indicate that the majority of the changes in the computed $\left(\mathrm{C}_{\mathrm{N}}\right)_{\mathrm{C}}$, due to the protuberances occur ahead of the frustum about mid upper stage at WT Re. In addition, the presence of the protuberances causes an increase in the vehicle's overall normal force coefficients at these flow conditions. Similarly, the results on the right hand-side of the figure indicate a moderate drop in the computed $\left(\mathrm{C}_{\mathrm{N}}\right)_{\mathrm{C}}$ with increasing Re from WT to FLT for the $\mathrm{C} 1$ configuration at $M=1.6$, and $\alpha=7^{\circ}$. Such a drop in the computed $\left(\mathrm{C}_{\mathrm{N}}\right)_{\mathrm{C}}$ becomes noticeable at about mid upper stage and can be attributed to the expected thinner boundary layer at FLT Re. More detailed comparisons of USM3D with wind tunnel data and the results from other CFD codes for ADAC_2A configuration are discussed in Pao et. al. [25] with an emphasis on the importance of protuberances presence on the vehicle's 
rolling moment coefficient. It should be noted that this particular OML definition was frozen in preparation for the manufacturing time requirement for various components leading into the Ares-IX vehicle and the subsequent flight test. The computational activities were continued to support the pre- and post-flight test and the results were reported by Bauer et. al. [26].

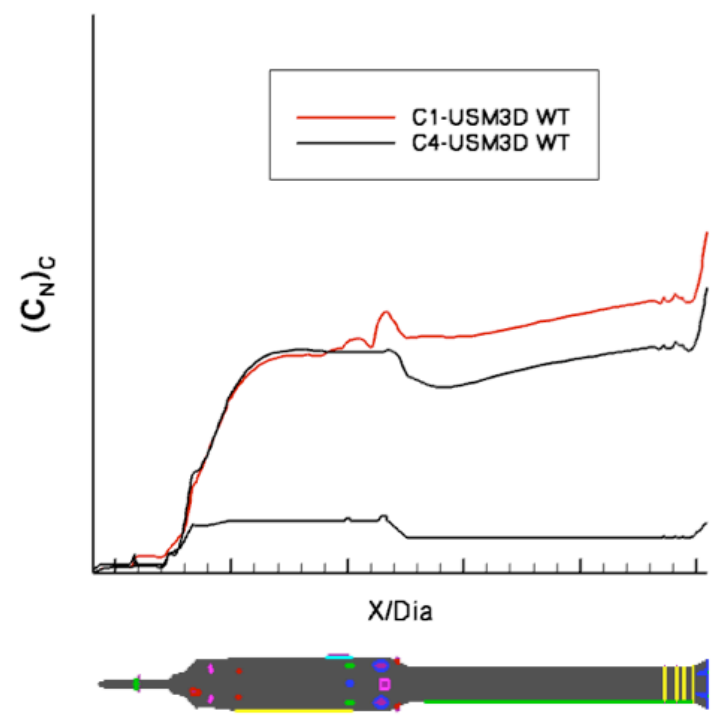

a)- Effects of protuberances

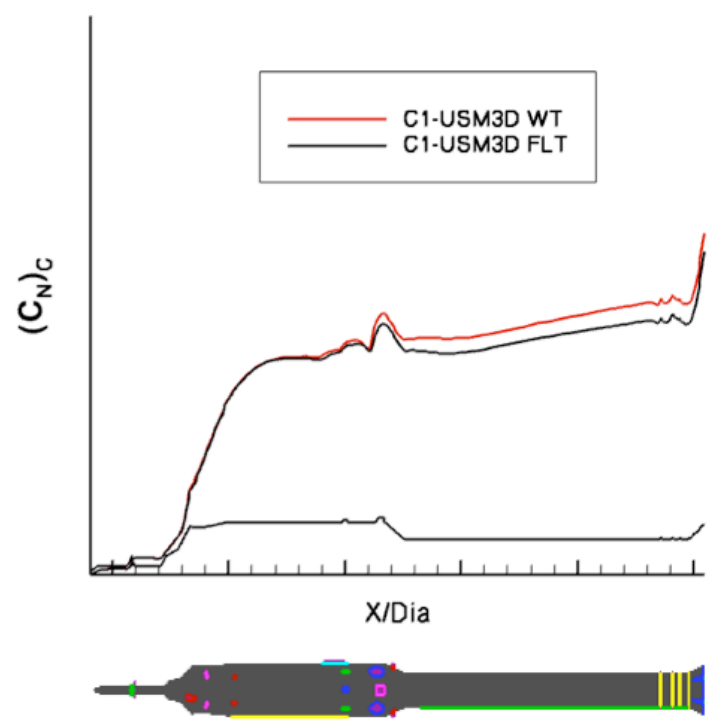

b)- Effects of $\operatorname{Re}$

Figure 12. Effects of protuberances and Re on Computed $\left(C_{N}\right)_{C}$ for the ADAC-2A (A101) configuration, $M=1.6, \alpha=7^{\circ}$.

\section{$\underline{\mathrm{ADAC}-2 \mathrm{~B}(\mathrm{A103})}$}

This section presents a sample of the CFD results [20] obtained at the nominal ascent flow conditions for the ADAC-2B (A103) configuration. This particular OML, released in early 2008, was subjected to an extensive wind tunnel testing [23, 24 and 27] that provided critical data to validate the computational results. The lessons learned, from the CFD analysis of the ADAC-2A configuration, on the importance of the protuberances and the roll angle on the vehicle's overall rolling moment coefficient were also incorporated and expanded under this activity in support of the GN\&C data requirement. As a result, the number of CFD solution development for this OML increased by nearly an order of magnitude to about 300 cases which resulted an increase in computer usage of about $1.5 \times 10^{6} \mathrm{CPU}$ hours.

Both the clean and the full protuberances vehicle geometries were studied. The computational results and the correlations with the experimental data are presented here first for the clean configuration followed by the analysis for the vehicle with full protuberances. All computed results are based on the SA turbulence model unless noted otherwise. Grid statistics in terms of total number of cells in the computational domain and surface triangles are shown in table 3 . 
Table 3. Surface and volume grid statistics for the ADAC-2B configurations.

\begin{tabular}{|c|c|c|c|}
\hline \multicolumn{2}{|c|}{ Clean } & \multicolumn{2}{c|}{ Full Protuberances } \\
\hline Volume Cells & Surface triangles & Volume Cells & Surface triangles \\
\hline$\sim 20 \times 10^{6}$ & $\sim 270,000$ & $\sim 49 \times 10^{6}$ & $\sim 770,000$ \\
\hline
\end{tabular}

At the outset, an extensive study was conducted on the clean configuration that addressed issues such as the solution sensitivity to grid refinement and the aerodynamic effects of modeling various height levels of small geometrical features such as the ramps, steps, and cavities. The results from the latter effort and the consultation with the experimental team identified the appropriate height levels for such small geometrical features from the $1 \%$-scale model manufacturing standpoint as well as the resulting aerodynamic impacts. Also, the results from the grid refinement study revealed the adequacy of a base grid $\left(\sim 20 \times 10^{6}\right.$ volume cells with $\sim 0.30 \times 10^{6}$ surface triangles) relative to a fine grid $\left(\sim 64 \times 10^{6}\right.$ volume cells with $\sim 0.6 \times 10^{6}$ surface triangles) for resolving the major aerodynamic characteristics of the clean configuration.

An efficient approach [28] was adopted for correlating the many measured surface pressure data points with the computational results and a sample comparison over the LAS/CEV and frustum regions are shown in figure 13 for $\mathrm{M}=1.6, \alpha=7^{\circ}$, WT Re. In this approach the measured surface Cp data, shown in color-coded circles, are superimposed over the background computed-results that are plotted over the same contour level and range. The experimental data here are measured with 115 ports, that are distributed non-uniformly along the top model surface meridian, at $\alpha=7^{\circ}, M=1.6$, and for $15^{\circ}$ roll angle increments. Thus any disagreements between the computed and measured data are highlighted by the changes in the color mapping. In general, the correlations between the two data are considered good.
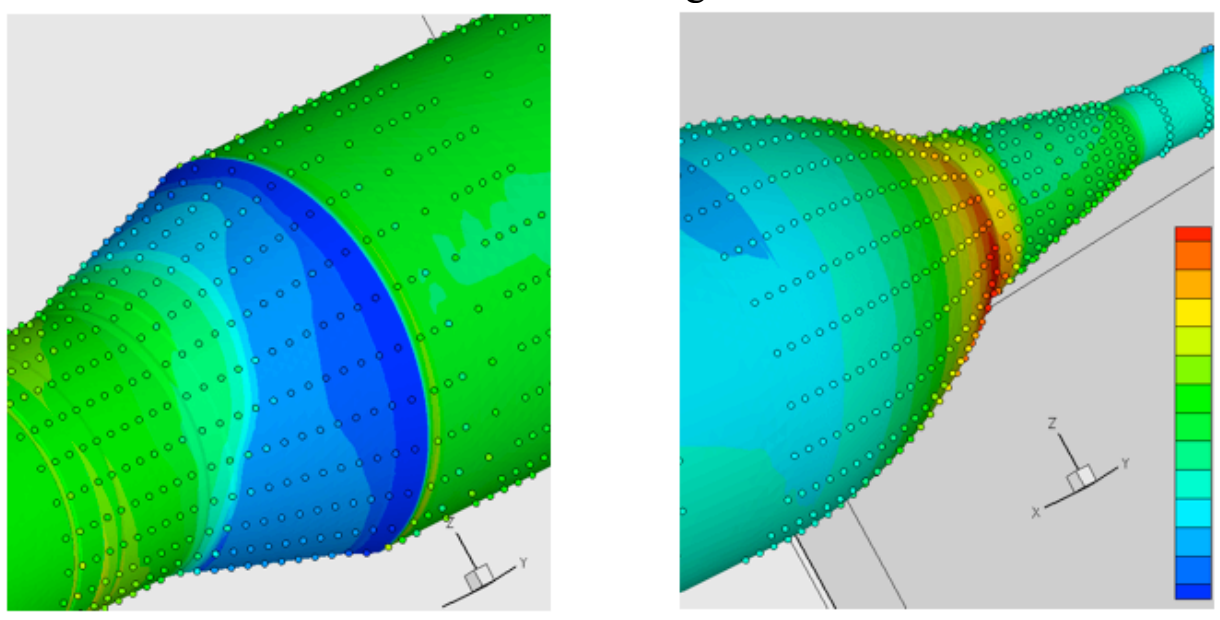

Figure 13. Computed and measured surface Cp on the clean ADAC-2B (A103) configuration, $M=1.6, \alpha=7^{0}$, WT Re.

The effects of Mach number on the computed and measured sectional line-loads over the frustum region of the clean configuration is shown in figure 14 for $\alpha=7^{\circ}, \Phi=0^{\circ}$, WT Re. The results indicate significant changes occurring over the region due to compressibility effects. 
Further analysis of the computed results revealed that such changes in the computed line-loads are primarily associated with a pocket of separated flow in the region and it's characteristics changes with Mach number. The trends and the large variations in the measured line-loads due to compressibility effects have been predicted reasonably well by the method.

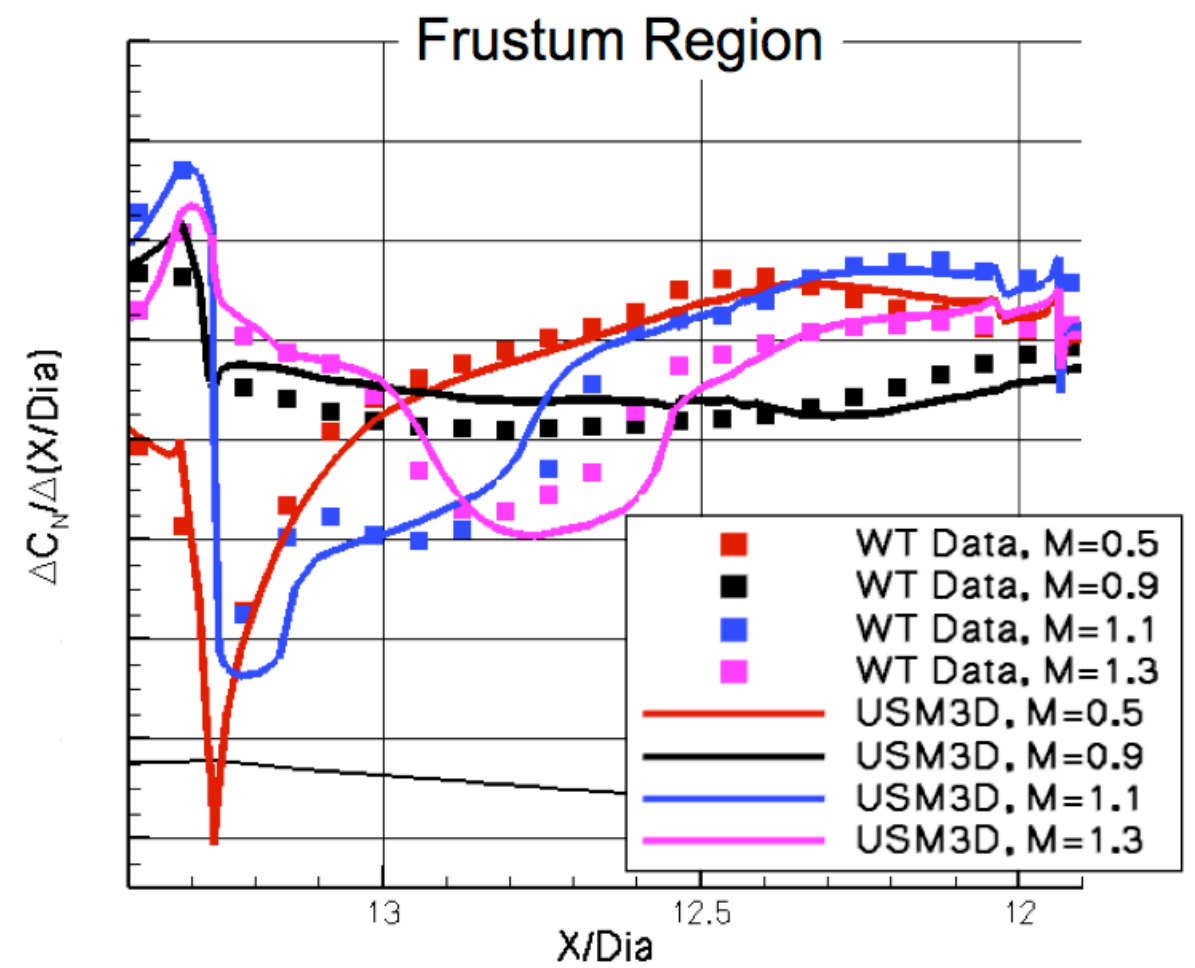

Figure 14. Computed and measured line loads over the frustum for the clean ADAC-2B (A103), $\alpha=7^{0}$, WT Re.

An effort was also made to assess the effects of different turbulence models on the computed results for the clean configuration. In addition to the SA, the two-equation SST and the $\mathrm{k}-\varepsilon$ turbulence models were selected for the study. The computations for this study were performed at $\alpha=7^{\circ}$, and WT Re. The effects of different turbulence models on various flow and/or aerodynamic properties such as surface flow pattern and pressure distribution, longitudinal normal and axial force distributions, total skin friction and its components, etc. were analyzed [20]. Such analysis, although not discussed here, also incorporated the complementary results from other CFD codes as well as the available experimental data. As an example, the effects of turbulence models on the computed $\mathrm{C}_{\mathrm{AF}}$ and $\mathrm{C}_{\mathrm{N}}$ for the clean configuration are shown in figure 15 as a function of Mach number at $\alpha=7^{\circ}$, WT Re. The variations of the computed $\mathrm{C}_{\mathrm{AF}}$ with different turbulence models were found to be about $10 \%$, and that generally the SST model predictions were closer to those of the SA model. The results also indicated that the two-equation models predict higher $\mathrm{C}_{\mathrm{N}}$ than the SA model at supersonic Mach numbers. In general, the results from this study, and those conducted earlier on the prior the OML configuration, revealed that the SA turbulence model was the most numerically robust, computationally efficient, and accurate in predicting the required aerodynamic data for this class of vehicles at the flow conditions of interest. 

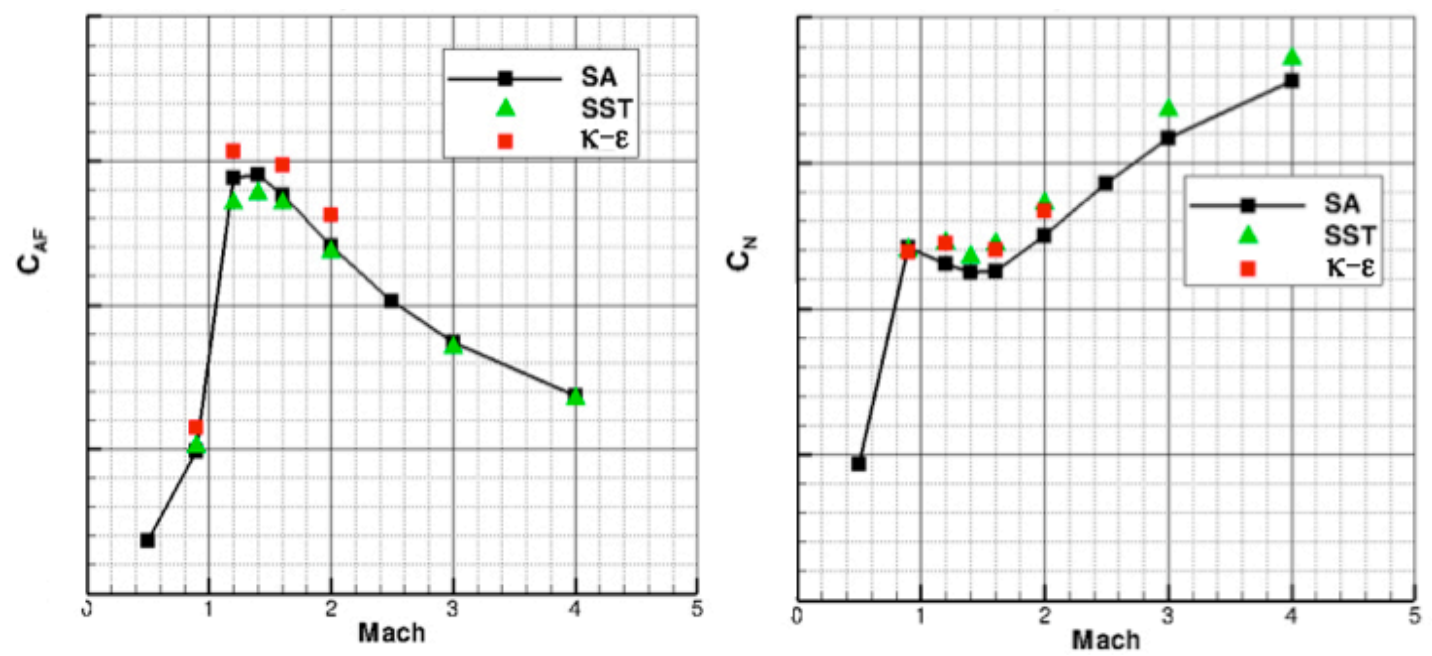

Figure 15. Computed $C_{A F}$ and $C_{N}$ with different turbulence model for the clean ADAC2B (A103), $\alpha=7^{\circ}$, WT Re.

The experience and the lessons learned from the grid generation on the prior configurations are used to develop a baseline grid for the ADAC-2B (A103) with full protuberances. This baseline grid contained $49 \times 10^{6}$ volume cells and $0.77 \times 10^{6}$ surface triangles. Close-up views of the surface grid for three regions of the vehicle are shown in figure 16. The surface grids are generally clustered around the region where large changes occur in the local geometry such as the LAS/CEV juncture and/or any of the protuberance/body intersections.
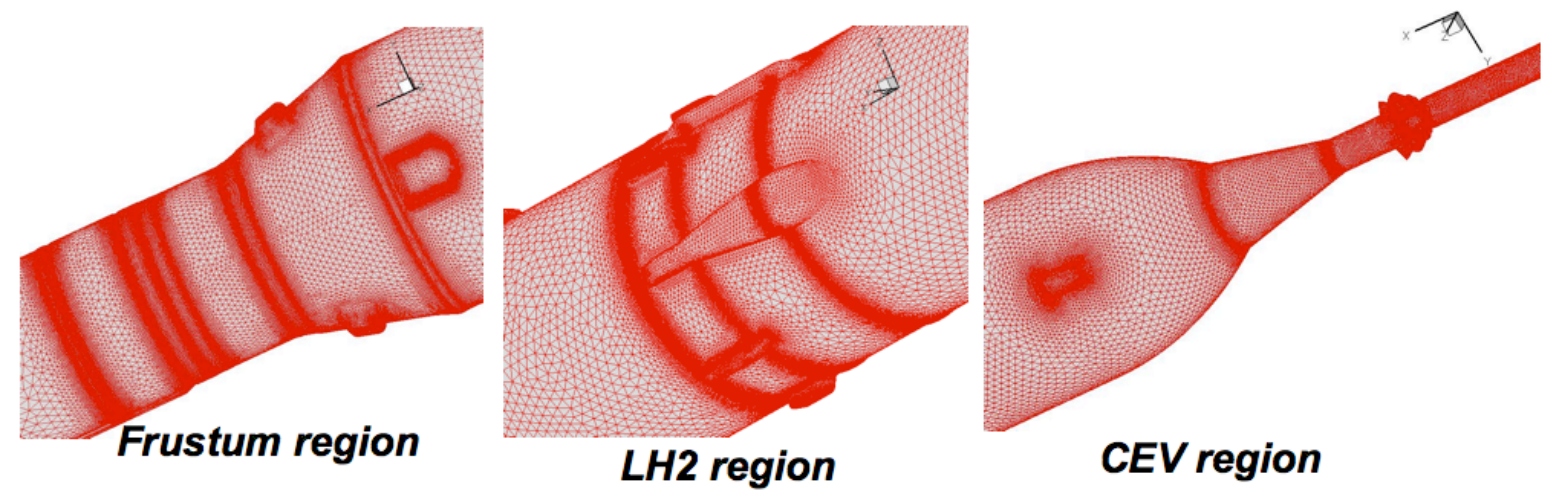

Figure 16. ADAC-2B (A103) computational grid.

The baseline grid was used for the computations at the nominal ascent flow conditions using the SA turbulence model. Unlike the axisymmetric surface geometry of the clean configuration, computations for the vehicle with full protuberances were performed at various roll angles, typically ranging from $0^{\circ}$ to $360^{\circ}$ with $30^{\circ}$ increments. Sample results that show the effects of protuberances at $\Phi=0^{\circ}$ and at other roll angles on the computed sectional line-loads at $\mathrm{M}=1.6$, $\alpha=7^{\circ}$, WT Re are presented in figure 17 for the front portion of the vehicle. The corresponding geometry segment is included at the bottom to help with visual feature identification. The local effects on the computed line-loads due to protuberances and various roll angles are significant. However, such effects, as demonstrated by the umbilical cover (i.e., X/Dia 21.6), appear to be relatively local and not longitudinally cumulative. As a result, the variations in computed lineloads diminish to an approximately the same level at about mid upper stage. 


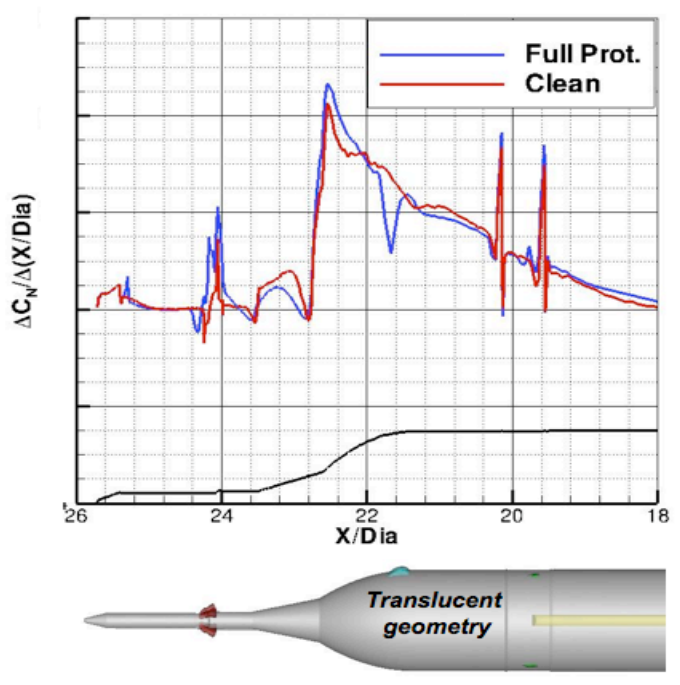

a)- Effects of protuberances

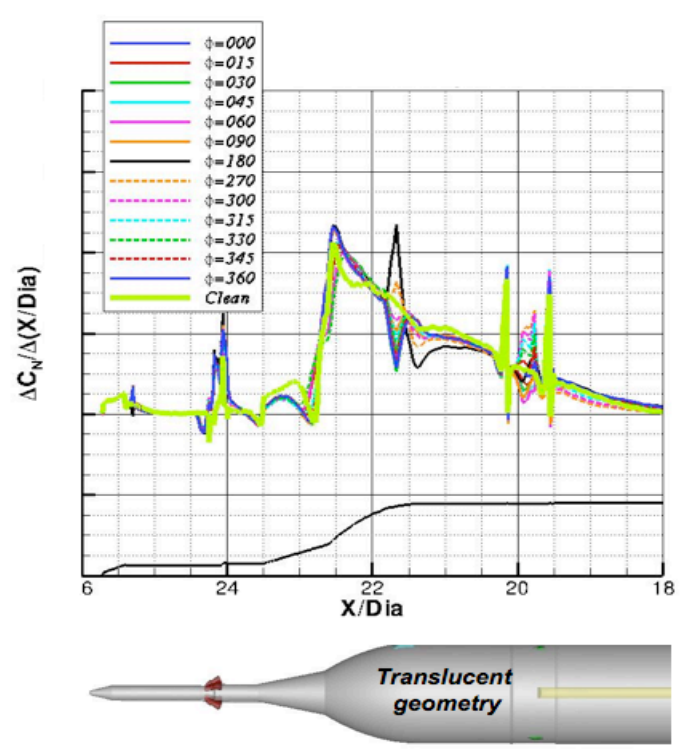

b)- Effects of roll angle

Figure 17. Computed effects of protuberances with roll angle on the ADAC-2B (A103), $\mathrm{M}=\mathbf{1 . 6}, \alpha=7^{\mathbf{0}}$, WT Re.

Limited surface $\mathrm{Cp}$ measurements have been obtained on the configuration with full protuberances that can be used for a partial validation the computational results. As discussed earlier, such limited sets of data are not dense enough over the vehicle to accommodate for an accurate integration of the sectional line-loads. These surface $\mathrm{Cp}$ data have been measured along the model top centerline, similar to the clean configuration, as well as some around a few major protuberances such as the LH2, the umbilical cover and the upper stage tunnel system. As a result, these surface $\mathrm{Cp}$ data along with the measured total forces and moments are the primary sources of the experimental data that have been used to validate the computational results for the configuration with full protuberances.

Sample computed and measured surface Cp at $\alpha=7^{\circ}$, WT Re, for the Mach numbers of 1.6 and 0.9 for the configuration with full protuberances are shown in figures 18 and 19. The experimental data have been obtained from the PSWT [24]. In addition to the top centerline, the correlations between the computed and measured data are also shown for two rows: one above and the other below the LH2. With exception of some differences over the frustum and the aftskirt regions, the comparison of results indicates a reasonable agreement, both in terms of trends and magnitudes, between the measurements and the predictions at both Mach numbers. Although limited to a small region, such comparisons provide some degree of confidence in the numerical predictions of the surface flow characteristics. 


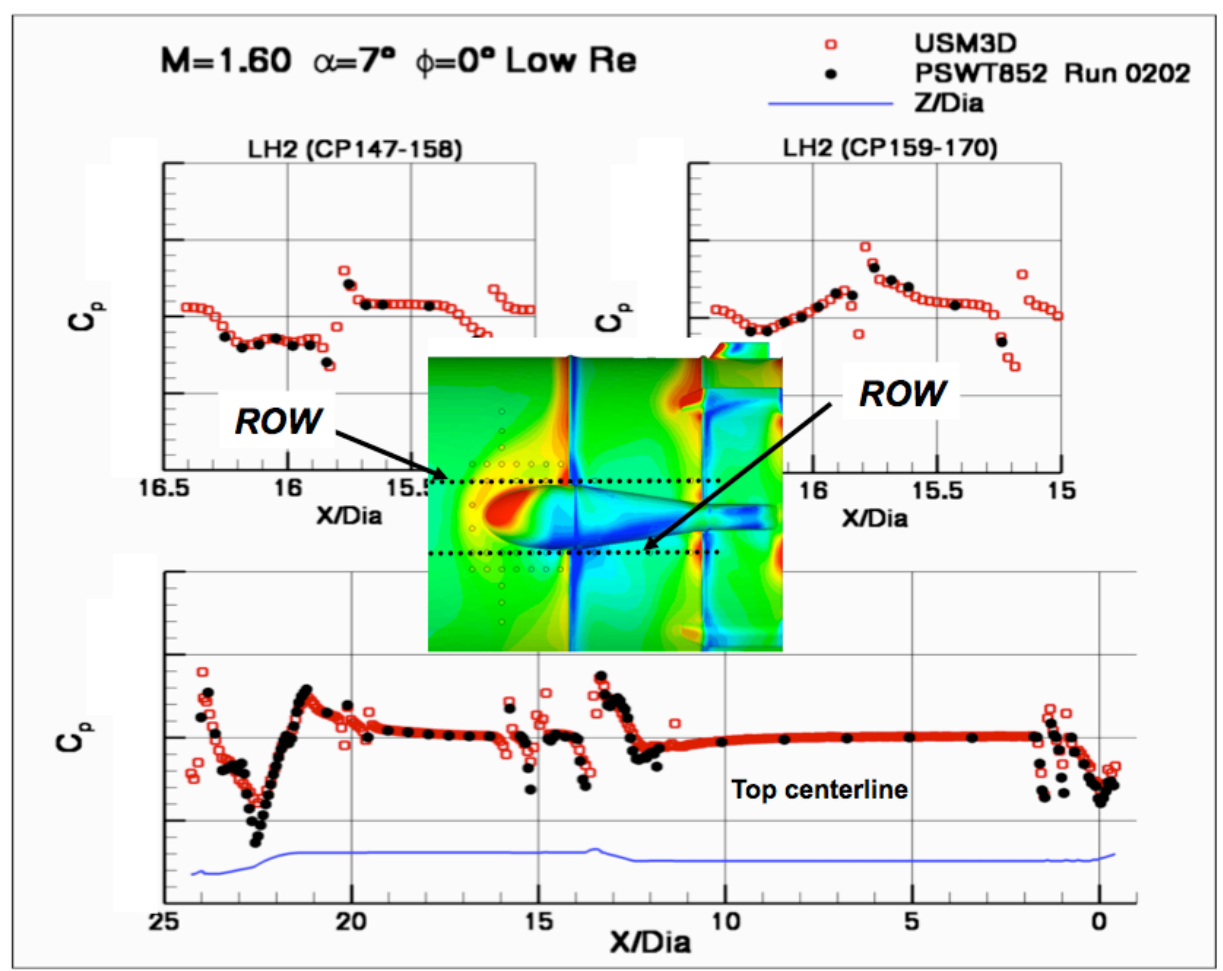

Figure 18. Computed and measured surface Cp on the ADAC-2B (A103) configuration, $M=1.6, \alpha=7^{\circ}, \mathrm{WT}$ Re.

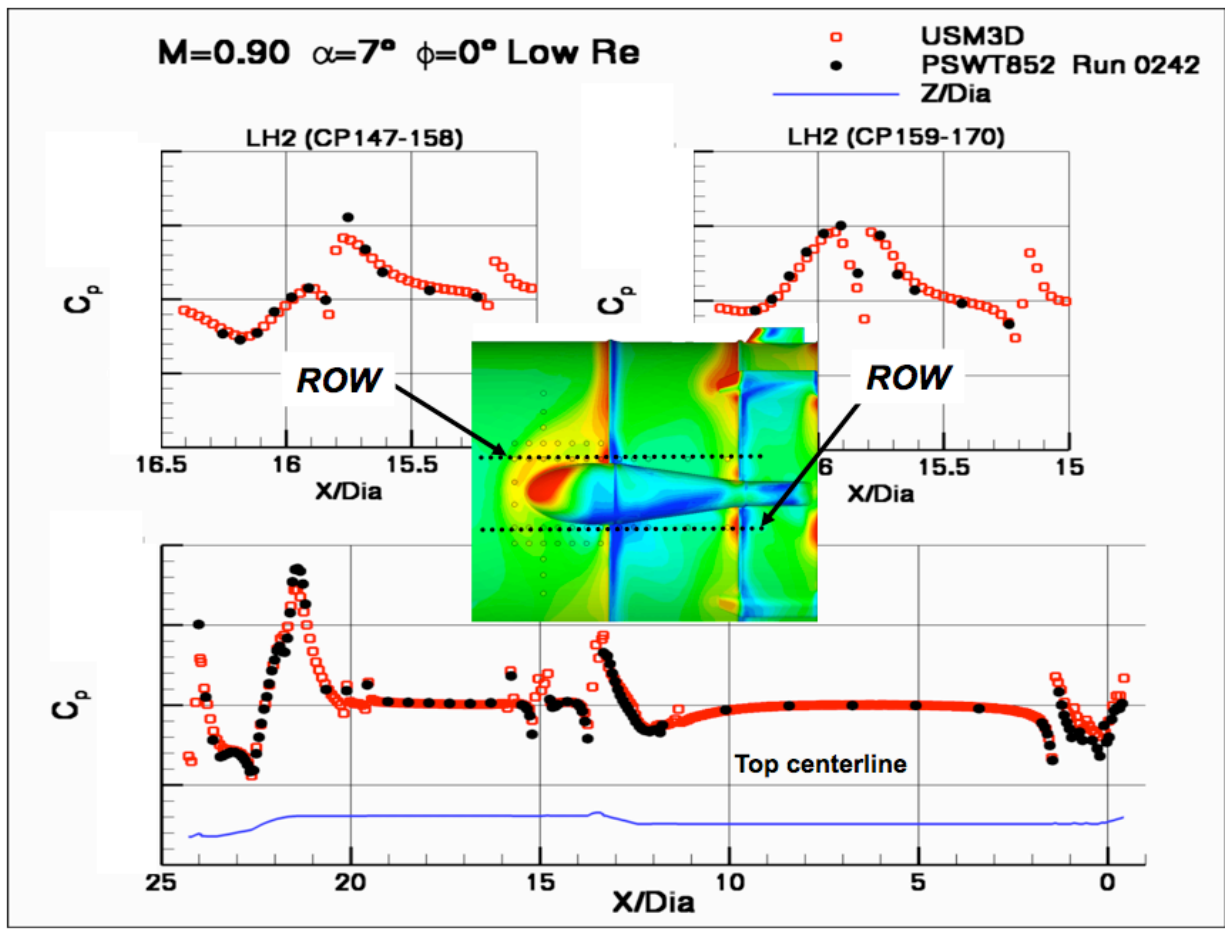

Figure 19. Computed and measured surface Cp on the ADAC-2B (A103) configuration, $\mathrm{M}=0.9, \alpha=7^{0}, \mathrm{WT}$ Re.

American Institute of Aeronautics and Astronautics 
Prior to the recent Ares-IX flight test [26], there was no experimental data available for this class of vehicles at flight Re that could be used to validate the computational results. As a result, an effort was initiated to measure a limited set of high $\mathrm{Re}$ surface $\mathrm{Cp}$, that reached to approximately one tenth of the appropriate flight level, from the Langley's National Transonic Facility (NTF) at subsonic and transonic speeds (i.e., $0.5<\mathrm{M}<1.1$ ) to aid anchoring the slope of the extrapolation curve at the lower end. The NTF test was conducted using a 1\%-scaled model for both the clean and with the full protuberances geometries at selected flow conditions of interest for various Reynolds number with the tunnel running on the standard air mode (i.e., low $\mathrm{Re}$ ) as well as the cryogenic mode (i.e., High Re). The model was instrumented with pressure port distributions and flow conditions similar to the one tested in the PSWT that would provide an opportunity for a tunnel-to-tunnel data comparison at low Re.

All CFD solutions were completed and the results were delivered to the project office prior to the start of the NTF test to aid the planning and test matrix development by the experimental team. The details of the test results from the NTF and the correlations with the delivered CFD data along with the measurements from the PSWT can be found in reference 27. In general, the comparisons of the computed and measured surface $\mathrm{Cp}$, as well as the sectional line-loads were found to be in reasonable agreements for the clean ADAC-2B (A103) configuration for both the low and high Re flow conditions. Similarly, the measured surface $\mathrm{Cp}$ distributions for the model with the full protuberances, although limited, were also found to correlate well with the numerical predictions. A sample comparison of the computed and measured surface $\mathrm{Cp}$ distributions for the top centerline along two rows adjacent to the LH2, for the high Re case at M $=0.9, \mathrm{a}=7^{\circ}$, is presented in figure 20. The results indicate good correlations between the computed and measured data in terms of trends and magnitudes for different regions with the exception of some disagreements over the centerline around the frustum and the aft-skirt region.

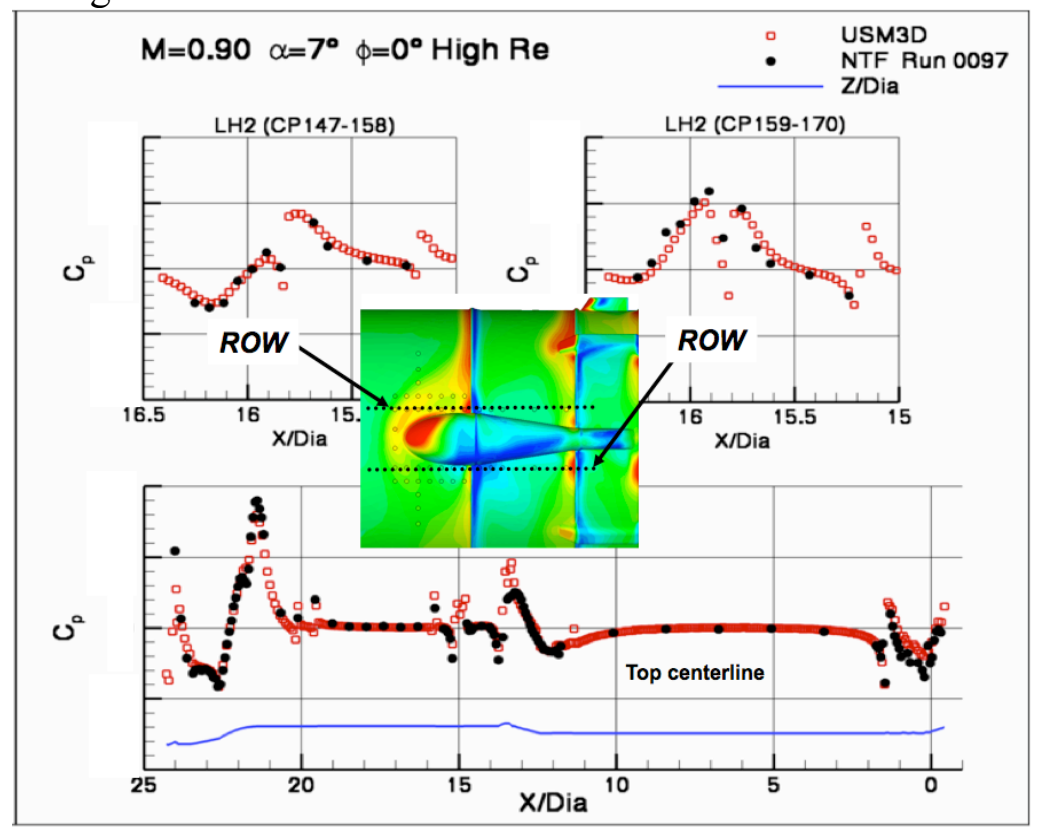

Figure 20. Computed and measured surface Cp on the ADAC-2B (A103) configuration at $M=0.9, \alpha=7^{0}$, high WT Re. 
The computed and measured $\mathrm{C}_{\mathrm{AF}}$ and $\mathrm{C}_{\mathrm{N}}$ for the $\mathrm{ADAC}-2 \mathrm{~B}$ (A103) configuration with the full protuberances are shown in figure 21 as a function of Mach number for various angles of attack. The wind tunnel measurements have been obtained from the PSWT for $\mathrm{M}<1.6$ and the Langley's UPWT for $M>1.6$. The increasing trends in the measured $\mathrm{C}_{\mathrm{AF}}$, with increasing $\alpha$, are predicted reasonably well across the examined Mach range, however, their magnitudes are slightly under-predicted. Similarly, the computed $\mathrm{C}_{\mathrm{N}}$ over predicts the magnitudes of the measured data at all examined angles of attack, especially at low supersonic Mach numbers. However, the increasing trend in the measured $\mathrm{C}_{\mathrm{N}}$, with increasing angle of attack, is predicted reasonably well across the Mach range.
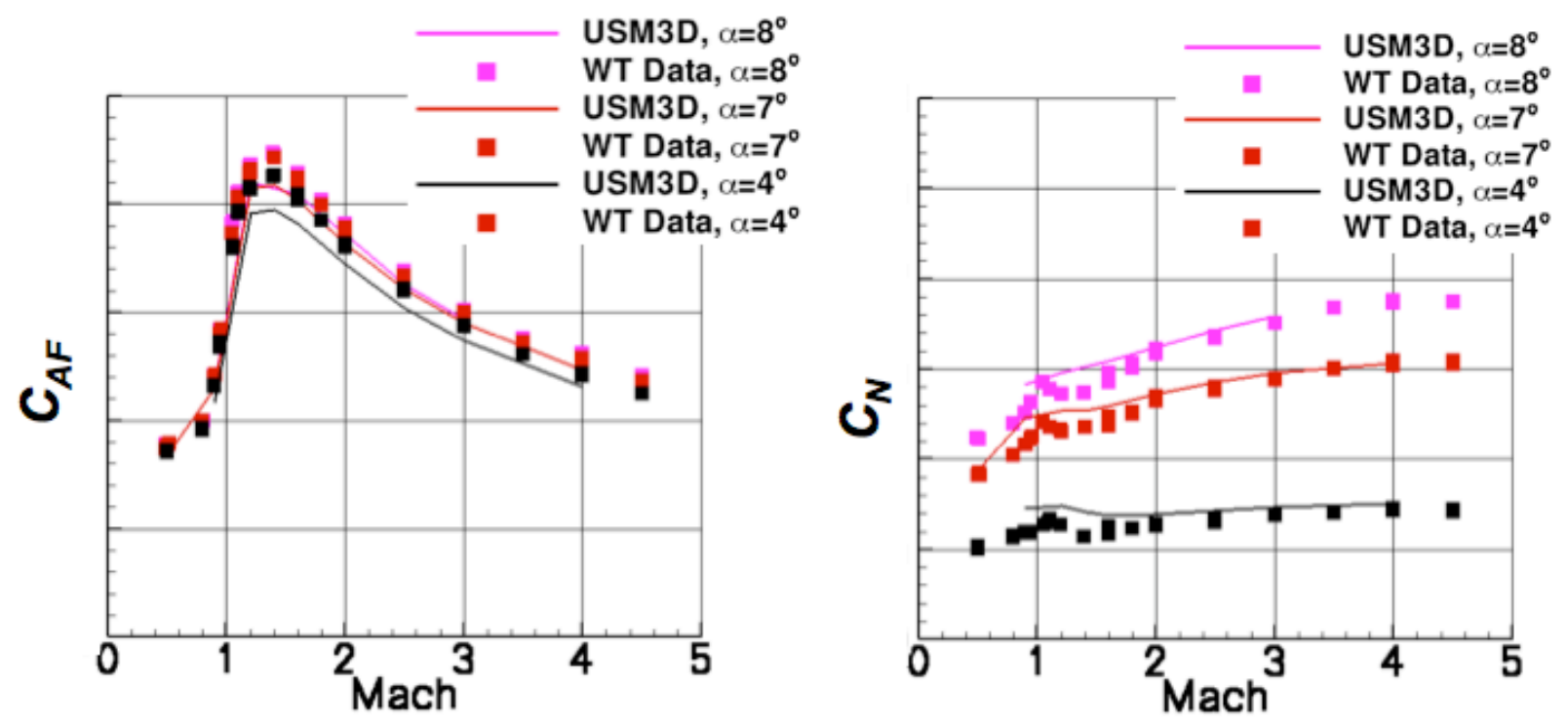

Figure 21. Computed and measured $C_{A F}$ and $C_{N}$ at various angles of attack for ADAC2B (A103), WT Re.

\section{$\underline{\operatorname{ADAC}-3(\mathrm{A106})}$}

In early 2009, the latest A106 OML was released ahead of Critical Design Review (CDR). The most extensive computations so far in this project were performed on this particular OML to address an update for the aerodynamic effects due to various parameters such as angles-of-attack, Mach number, roll angle, at both the wind-tunnel and flight Reynolds number [21]. In response to the additional requirements and support of other elements within the project, there were about 1,000 CFD solutions developed for this particular OML that consumed about $3 \times 10^{6}$ CPU hours. Sample results and trends in the computed aerodynamic data are presented here for the typical flow features, the sectional line-loads, the longitudinal aerodynamic coefficients, the rolling moment, and the center of pressure movement at representative ascent free-stream flow conditions and roll angle. Although no experimental data is used in this section, but based on the lessons learned from the prior verification/validation activities, it is believed that the present method's viability for such application has already been demonstrated. 
Table 4. Surface and volume grid statistics for the ADAC-3 (A106) configuration.

\begin{tabular}{|c|c|c|c|}
\hline \multicolumn{2}{|c|}{ ADAC-3 (WT Re) } & \multicolumn{2}{c|}{ ADAC-3 (FLT Re) } \\
\hline Volume Cells & Surface triangles & Volume Cells & Surface triangles \\
\hline$\sim 70 \times 10^{6}$ & $\sim 1.0 \times 10^{6}$ & $\sim 90 \times 10^{6}$ & $\sim 1.0 \times 10^{6}$ \\
\hline
\end{tabular}

The early 2009 released OML for the A106 configuration was used to generate the computational surface and the flow field volume grids. The complete configuration with full protuberances was modeled with approximately one million surface triangles and representative surface grid distributions are shown in figure 22 for three different regions. This surface grid was used to generate the corresponding volume grids of roughly $70 \times 10^{6}$ and $90 \times 10^{6}$ cells for the computations at the WT and FLT Re, respectively, as shown in table 4. The field grid used for the computations at flight Reynolds number incorporated a smaller height for the first cell normal spacing to resolve the expected thinner boundary layer and thus increased the total cell size by about $20 \times 10^{6}$ relative to the grid size used for the WT Re computations.

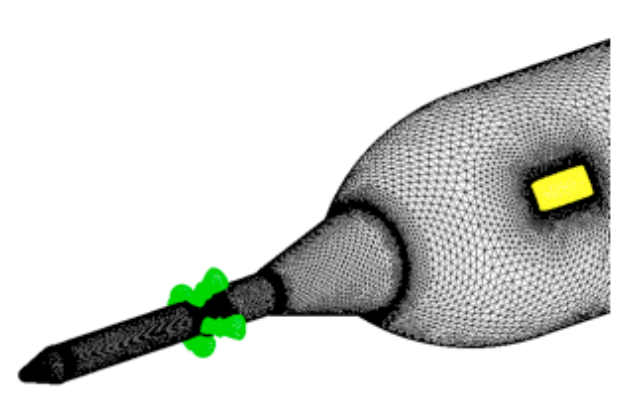

LAS/CEV region

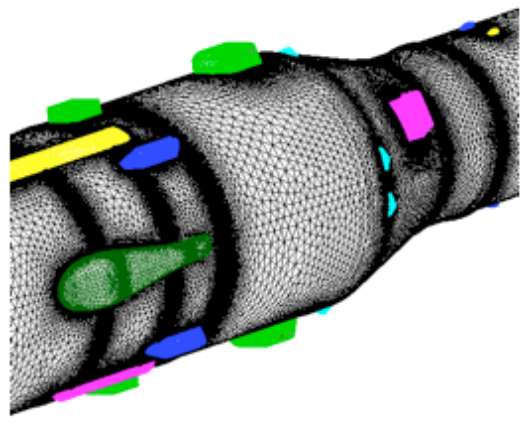

LH2/Frustum region

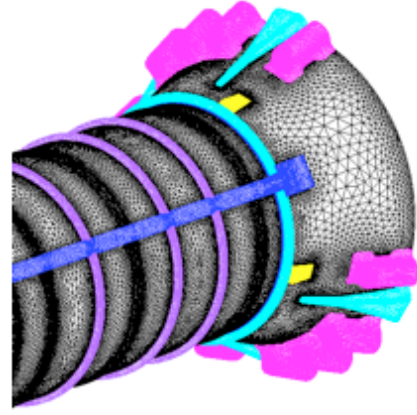

Aft-skirt region

Figure 22. Computational surface grid for the ADAC-3 (A106).

Sample low supersonic flow features computed at $M=1.6, \Phi=0^{\circ}$, WT Re, for $\alpha=0^{\circ}$, and $\alpha$ $=8^{\circ}$ are shown in figure 23. This Mach number is near the maximum dynamic pressure point along the ascent trajectory. The results show the computed surface pressure coefficient and the off surface Mach number contours. The off surface Mach contours, computed at $\alpha=0^{\circ}$, show the expected initial bow shock forming ahead of the LAS nose followed by many other shock waves generated downstream over the body due to either the presence of a protuberance and/or surface geometry discontinuities. The low Mach number separated regions ahead and behind the ReCS and the RoCS seem to be small and do not appear to spill over onto the frustum.

The computed flow features at $\alpha=8^{\circ}$ show a significant difference, as expected, between the top and the bottom half of the vehicle. The results show weakened shock waves on the windward side on the front LAS/CEV section whereas they become strengthened further down stream over the ReCS, RoCS and the frustum region. In an effort to highlight the separated regions, the portside view of the computed axial force component of the surface skin friction coefficients are shown in figure 24. In this figure, any reversed flow region is highlighted by the variations of the 
surface color contours. The results indicate a region of separated flow ahead of the LAS nozzles, over the CEV/ramp juncture and the first stage/frustum juncture, as well as around the BTM on the frustum.
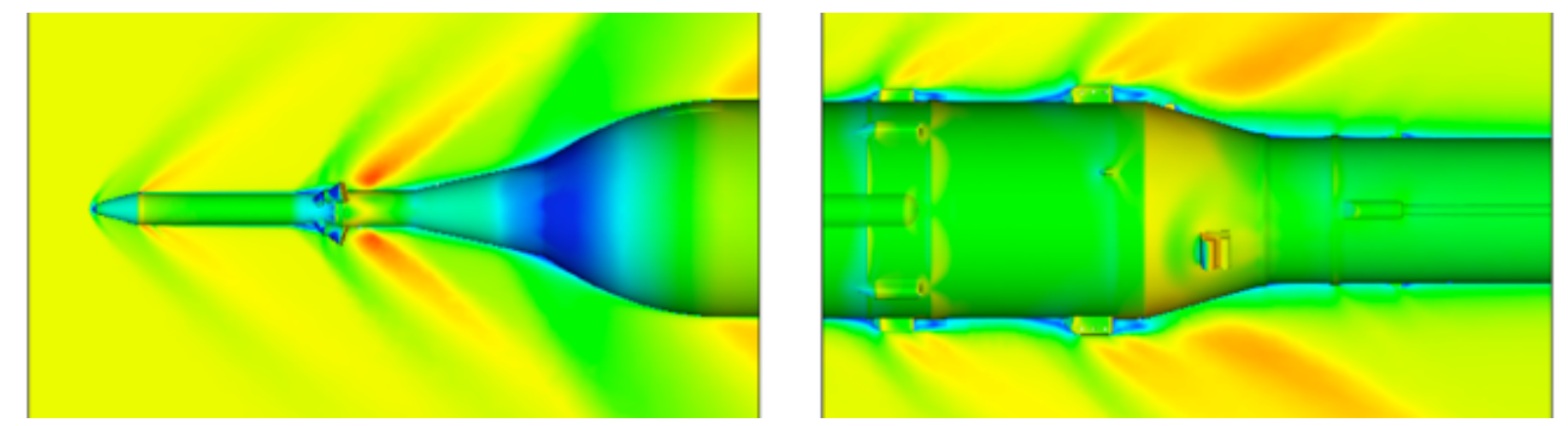

a) $-\alpha=0^{\circ}$
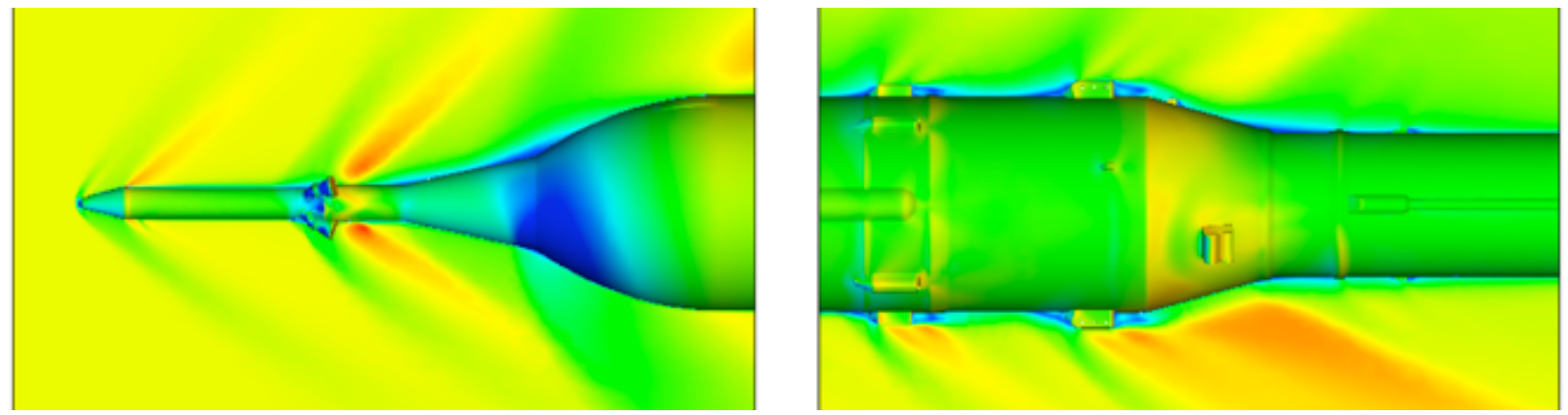

b)- $\alpha=8^{\circ}$

Figure 23. Computed surface $C p$ and off-surface Mach contours for the ADAC-3 (A106) at $M=1.6, \Phi=0^{\circ}$, WT Re, portside view.
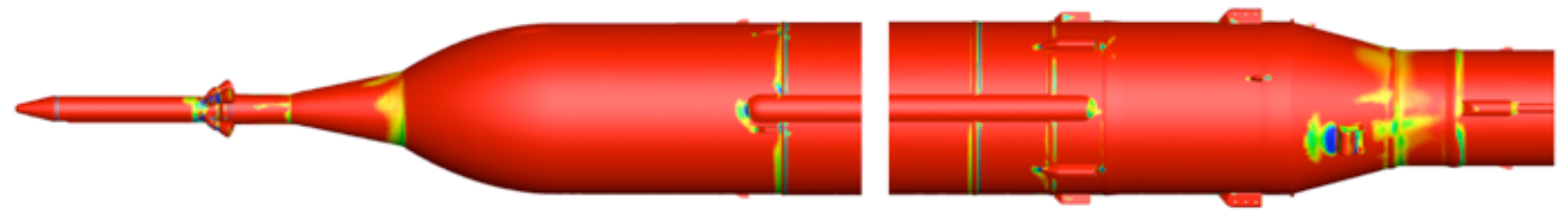

Figure 24. Computed surface axial force component of the skin friction for the ADAC-3 (A106) at $M=1.6, \alpha=8^{\circ}, \Phi=0^{\circ}$, WT Re, portside view.

The sectional line-load distributions computed at $M=1.6$ and $\Phi=0^{\circ}$ for various angles of attack are shown in figures 25 . The results are presented with the focus on two sections of the vehicle: the LAS/CEV and the frustum section. Also, an approximate representation of the A106 geometry profile is shown below the line-load plots to aid visual feature identification of axial locations. The results indicate, as expected, a nearly zero line-load distribution at $\alpha=0^{\circ}$. At this angle-of-attack, any finite values of line-loads can be attributed to the geometrical asymmetry (i.e., protuberances) such as the LAS nozzles $(\mathrm{X} / \mathrm{Dia} \sim 24)$. Note that the most significant load computed at $\alpha=0^{\circ}$ is occurring aft of the Interstage/frustum juncture where there are several asymmetrically positioned protuberances. As expected, the results generally show an increasing 
trend in the sectional line-load with increasing angle of attack with the exception of some variations over the frustum.

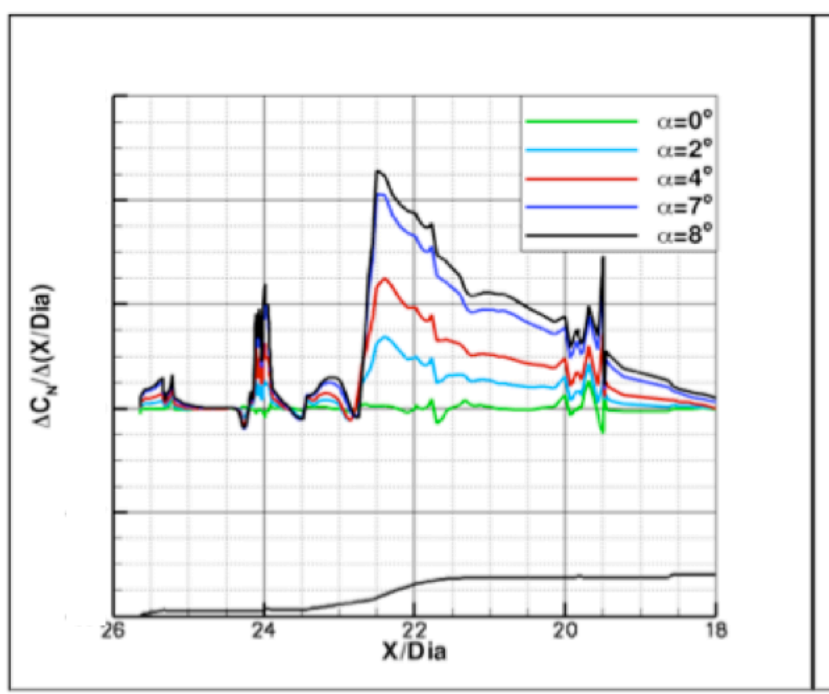

a)- $\mathrm{LAS} / \mathrm{CEV}$ region

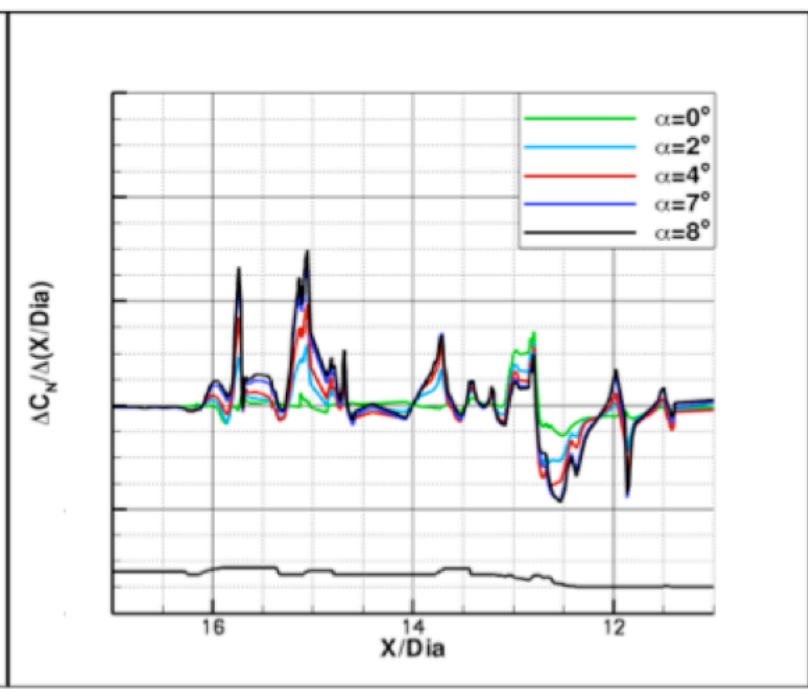

b)- Frustum region

Figure 25. Effect of angle of attack on sectional line-loads for the ADAC-3 (A106) at M $=1.6, \Phi=0^{\circ}$, WT Re.

The effects of roll angle on the sectional line-loads, computed at $\mathrm{M}=1.6$ and $\alpha=8^{\circ}$, are presented in figure 26 . The results at these selected roll angles indicate only a small change in the sectional line-loads over the LAS/CEV region, except around X/Dia $\sim 19.8$ where there are a few asymmetrically positioned protuberances. Also, the sharp spike in the sectional line-loads at $\mathrm{X} / \mathrm{Dia} \sim 19.5$ is due to the presence the first ring on the upper-stage. Unlike ADAC-2B (A103), figure $17 \mathrm{~b}$, the smaller size umbilical cover for the present configuration eliminates nearly all the oscillations in the sectional line-loads (i.e., X/Dia 21.6) with roll angle. The results also reveal a significant variation, due to roll angle, in the computed line-loads around the aft part of the upper stage and the frustum region. These large variations are caused by the flow interactions with many protuberances in the region such as the LH2, Upper Stage system and pressure tunnels, RoCS, and several other components. 


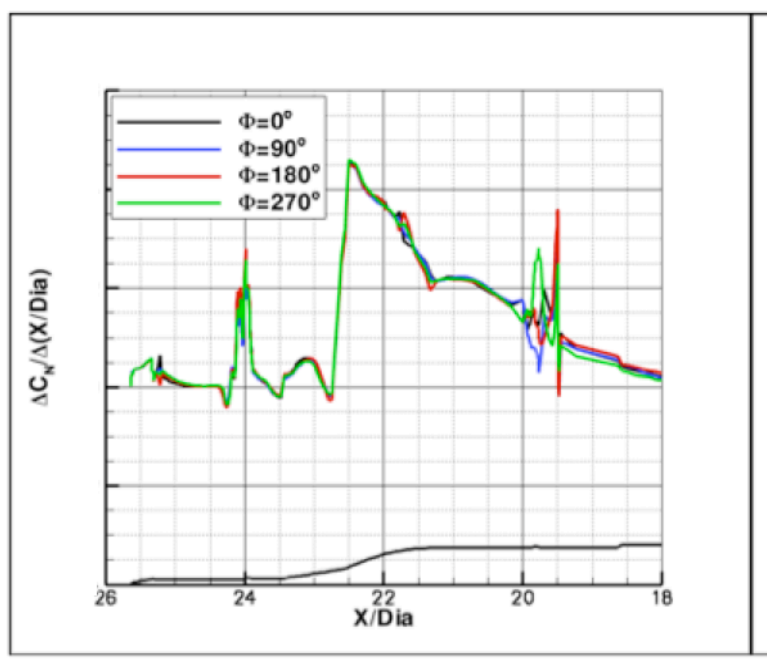

a)- LAS/CEV region

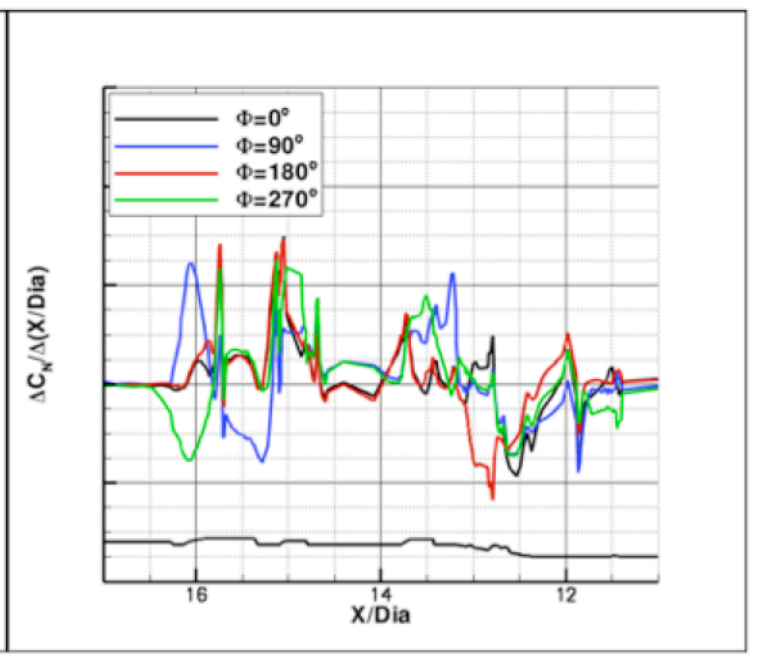

b)- Frustum region

Figure 26. Effect of roll angle on sectional line-loads for the ADAC-3 (A106) at $M=1.6$, $\alpha=8^{\circ}$, WT Re.

The effects of Mach number on the sectional line-loads, computed at $\alpha=8^{\circ}, \Phi=0^{\circ}$, are presented in Figure 27. The results show significant effects on the sectional line-loads due to Mach number. Such significant effects occur over the front part of the vehicle around the $\mathrm{CEV} /$ ramp juncture $(\mathrm{X} / \mathrm{Dia} \sim 22.5)$, CEV shoulder $(\mathrm{X} / \mathrm{Dia} \sim 21.7)$, and the first ring on the upper stage $(\mathrm{X} / \mathrm{Dia} \sim 19.5)$. In general, the sectional line-loads show an increasing trend with Mach number over the CEV followed by a reversing trend after the shoulder (X/Dia 21.8). Also, the maximum value of the sectional line-load occurs over the CEV (X/Dia 22.4) at $\mathrm{M}=4.5$. The effects of the protuberances on the computed line-load over the frustum region appear to be most pronounced at $\mathrm{M}=0.9$ with a diminishing trend as the Mach number is increased.

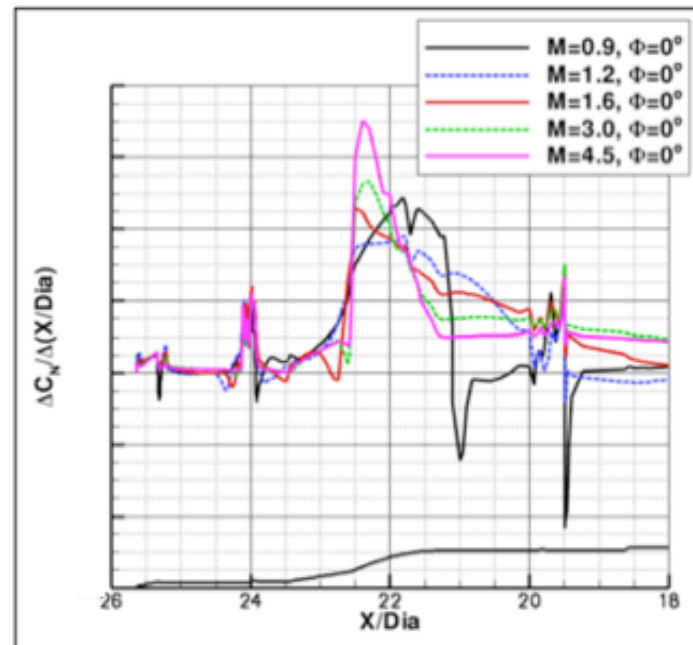

a)- $\mathrm{LAS} / \mathrm{CEV}$ region

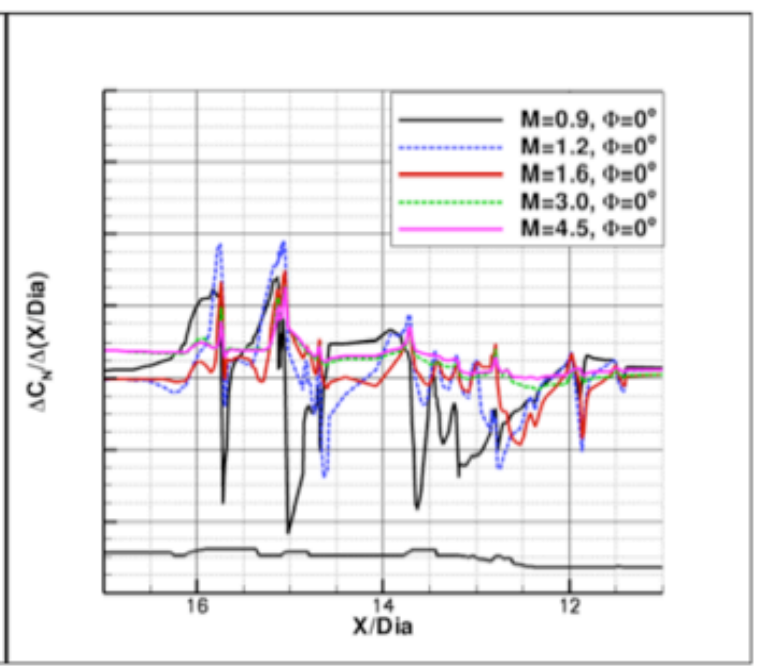

b)- Frustum region

Figure 27. Effect of Mach number on sectional line-loads for the ADAC-3 (A106) at $\alpha=$ $8^{\circ}$, WT Re. 
The effects of vehicle's roll angle on the computed $\mathrm{C}_{\mathrm{AF}}$ and $\mathrm{C}_{\mathrm{N}}$ over the examined Mach range at $\alpha=8^{\circ}$, WT Re, is shown in figure 28. The results indicate minimal roll angle effects on the computed $\mathrm{C}_{\mathrm{AF}}$ at all Mach numbers and the maximum level occurs at $\mathrm{M} \sim 1.2$. However, the effects of roll angle on the computed $\mathrm{C}_{\mathrm{N}}$ become more pronounced. The largest variations of the computed $\mathrm{C}_{\mathrm{N}}$ with the roll angle occur at transonic and low supersonic speed range where it reaches to $\sim 15 \%$. Although not included here, further analysis of the computed flow features, sectional line loads as well as cumulative line loads indicated that the majority of the oscillations in $C_{N}$ with roll angle at transonic and low supersonic speed range is due to the presence of many asymmetrically positioned protuberances over the aft-skirt.

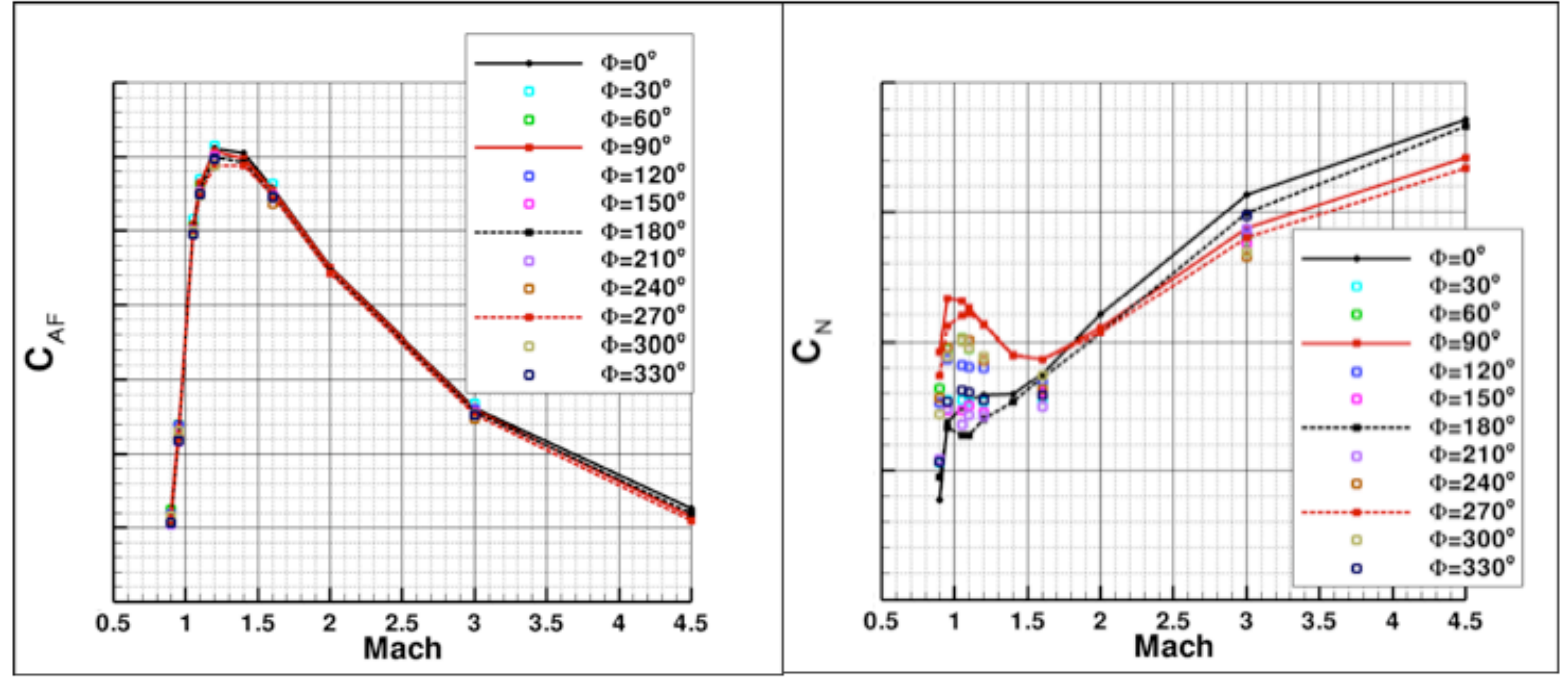

Figure 28. Effect of roll angle on the computed $C_{A F}$ and $C_{N}$ for the ADAC-3 (A106) at $\alpha=8^{\circ}$, WT Re.

A sample rolling moment coefficients computed at $\alpha=8^{\circ}, \mathrm{M}=1.6$, and WT Re, for the ADAC-3 (A106) configuration is shown in figure 29. In addition to the total $C_{R M}$ for the vehicle (denoted as A106), the figure also shows the corresponding contributions from the major protuberances such as a106_fp (i.e., A106 footprint: vehicle's body with all protuberances removed), LH2, upper stage system tunnel (USTTUN), upper stage pressure tunnel (PressTun) Wedges, and etc. The results show that the maximum $C_{R M}$ for the vehicle occurs at $\Phi=0^{\circ}$ and $180^{\circ}$, and that the largest contributor to the total from the protuberances comes from the upperstage LH2 tank fairing (its contribution is higher than the vehicle's total). Other protuberances with a large contribution to the total $C_{R M}$ include the BDM's, USTTUN, FSTTUN, RoCS, PressTun, ReCS, and a106_fp. Access to such data was found to be useful and was subsequently employed in several trade studies with the goal to reduce and thus improve the overall level of the vehicle's rolling moment coefficients. Though not covered in this report, two approaches were investigated for such trade studies: one was through the circumferential redistribution of a selected protuberance (i.e., F/D-line, PressTun, BDM's, etc.) by holding the axial location fixed and the other was to vary the protuberance's height. Circumferential redistribution and the height variation of the selected protuberance were initially performed using the concept of superposition and the linear interpolation/extrapolation using the existing solutions. The accuracy of the results from such superposition and/or interpolation/extrapolation would later be verified for the most 
promising options through a dedicated simulation study where the geometry changes were actually modeled to verify its viability. The results from such trade studies were distributed to the project team members for information towards a possible design changes or modifications.

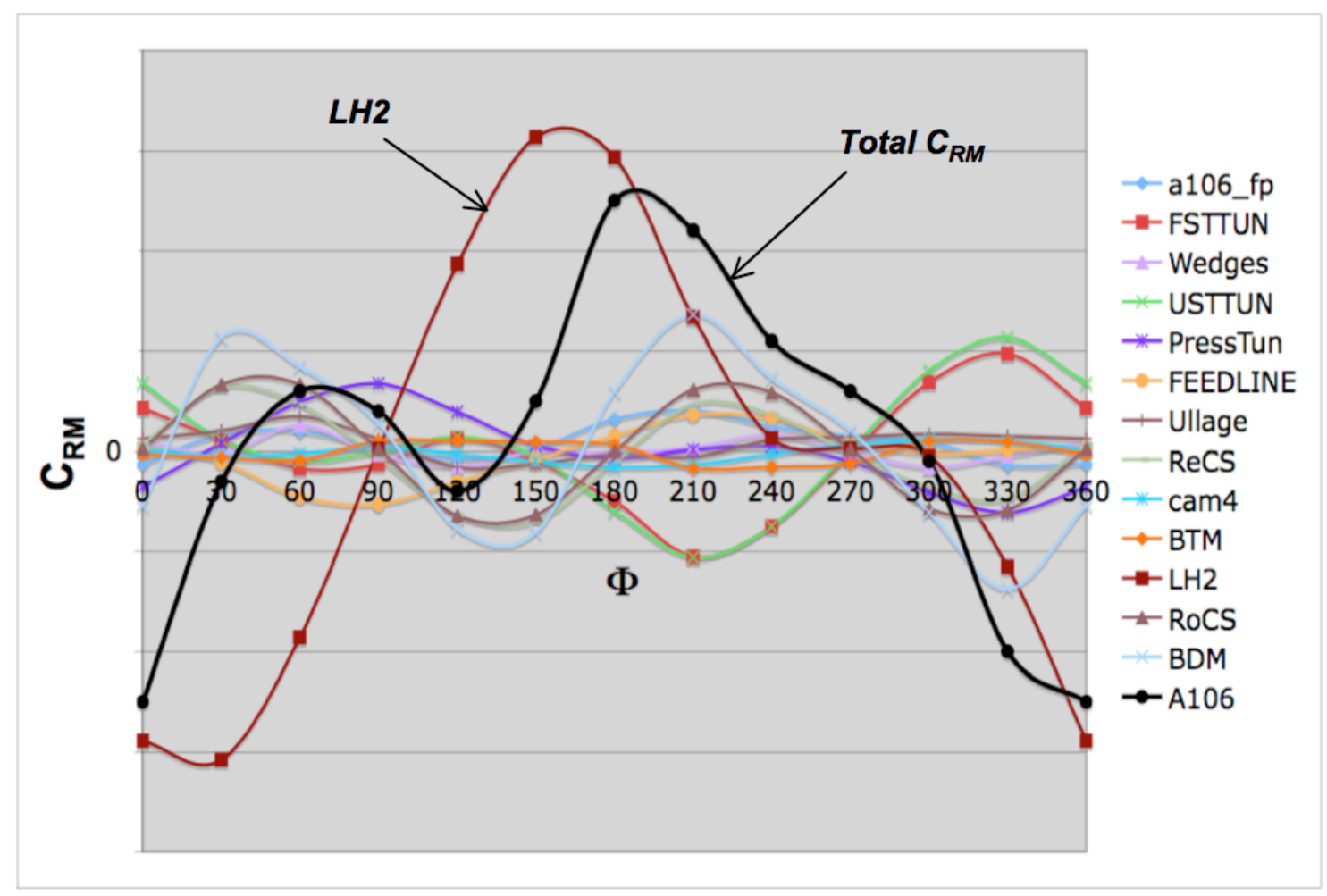

Figure 29. Computed total $C_{R M}$ and the contributions from the major individual or group of protuberance(s) for the ADAC-3 (A106) at $M=1.6, \alpha=8^{\circ}$, WT Re.

The ADAC-3 (A106) rolling moment coefficients and the center of pressure computed at $\alpha$ $=8^{\circ}$ are shown in figures 30 as a function of the roll angle $\Phi$, for various Mach number. The computed results indicate that the maximum $C_{R M}$ occurs at $M=1.6$ for $\Phi=0^{\circ}$ and $180^{\circ}$. The results also show a vanishing $\mathrm{C}_{\mathrm{RM}}$ trend with increasing Mach number due to lower dynamic pressure at higher altitudes. The center of pressure (CP) is simply the ratio of the computed pitching moment to the normal force coefficients. It is a measure of the $\mathrm{CP}$ movement relative to the vehicle's moment reference center (i.e., gimbal point of the main engine) in units of SRB diameter. The computed results show that there is a forward movement of the $\mathrm{CP}$ with increasing speed up to about Mach 3. The results also indicate that the variation of the CP movement in the axial direction, at transonic speeds $(0.9 \leq \mathrm{M} \leq 1.2)$, over the entire $\Phi$-range is significant and that the level of CP-oscillations with roll angles is reduced with increasing speed to a negligible level at $\mathrm{M}=4.5$. It should be noted that sample computed force and moment coefficients for the ADAC-3 (A106) configuration were subsequently correlated with the most recently obtained experimental data and the results are presented in reference 23 . 


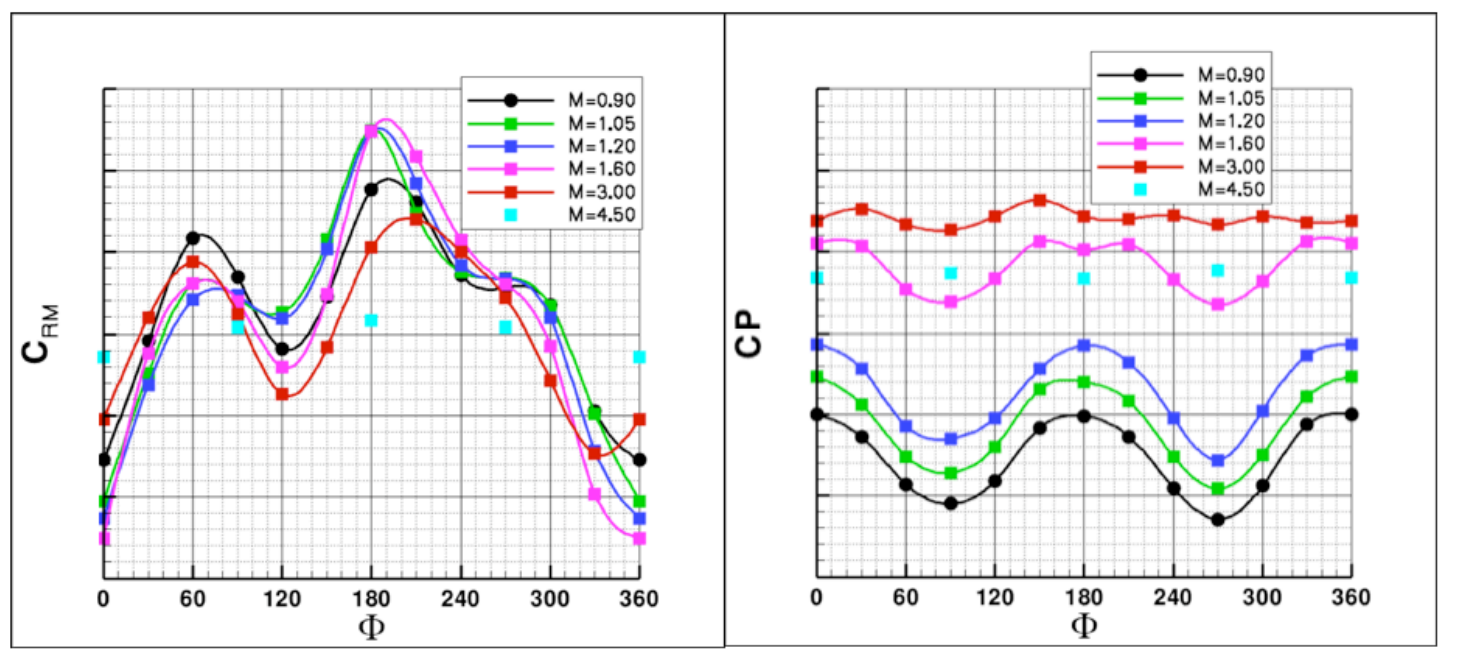

Figure 30. Computed total $C_{R M}$ and $C P$ at various Mach number for the ADAC-3 (A106) at $\alpha=8^{\circ}$, WT Re.

The computed incremental effects due to Re on the sectional line-loads for various roll angles at $M=1.6, \alpha=8^{\circ}$ are shown in figure 31. As expected, the results show that the most significant effects occur in the region where there is a large geometry change and thus the impact on local flow characteristics. Such regions, for the front portion of the vehicle, include the LAS nozzles (X/Dia 24.2), around the LAS ramp/CEV $(22 \leq \mathrm{X} / \mathrm{Dia} \leq 23.2)$, around the beginning part of the upper stage system tunnel and some smaller protuberances such as the cameras, antennae, ring, and brackets $(18.5 \leq \mathrm{X} / \mathrm{Dia} \leq 20)$. The incremental effects due to Re are more significant over the aft portion of the upper stage and frustum region where there are a number of geometrical changes. These geometrical changes include the frustum ramp, and many protuberances such as the LH2, F/D-line, four USM, two ReCS, two BTM, two rings, and the tail ends of the upper stage and pressure system tunnels. In general, the most significant incremental effects due to Re occur in the regions associated with the LH2 and F/D-line, the RoCS, and over the frustum ramp.

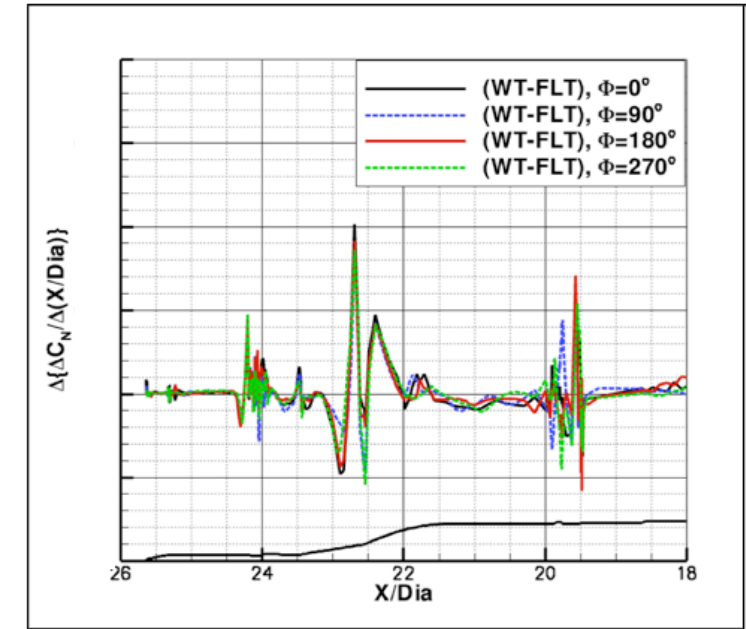

a)- LAS/CEV region

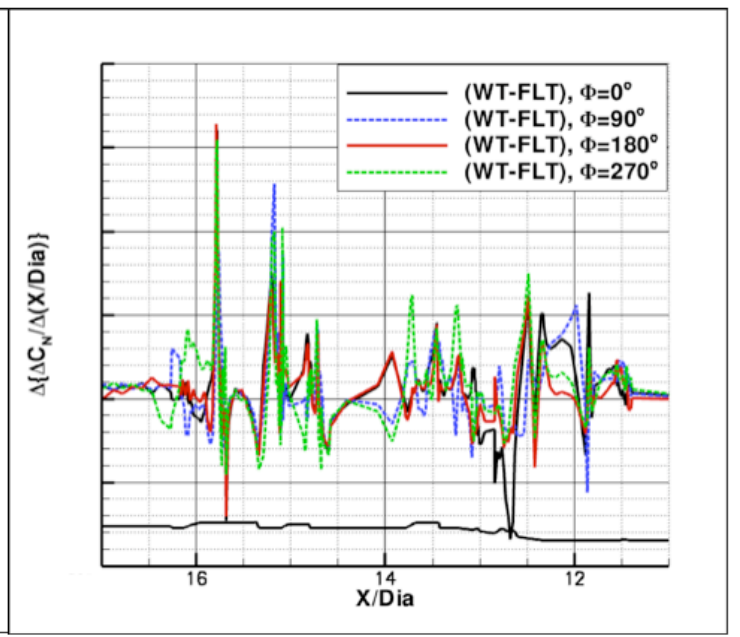

b)- Frustum region

Figure 31. Computed Re incremental effects on the line-loads at various roll angle for the ADAC-3 (A106) at $M=1.6, \alpha=8^{\circ}$. 
The computed incremental effects due to Re on the sectional line-loads for various Mach numbers at $\alpha=8^{\circ}, \Phi=0^{\circ}$ are shown in Figure 32. Such incremental effects, though generally small, become noticeable over the LAS nozzles, around the LAS ramp/CEV juncture, aft portion of the upper stage, and the frustum region. Also note the presence of a significant effect around $\mathrm{X} / \mathrm{Dia} \sim 21$ at $\mathrm{M}=0.9$ that was found to be associated with a small pocket of separated flow caused by a shock/boundary-layer interaction. In general, the results indicate that these incremental effects due to Re diminish with increasing Mach number over the vehicle.

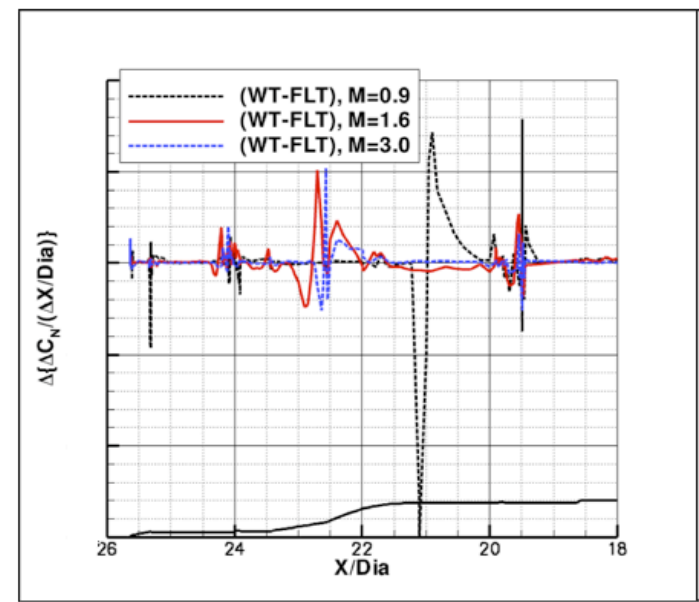

a)- LAS/CEV region

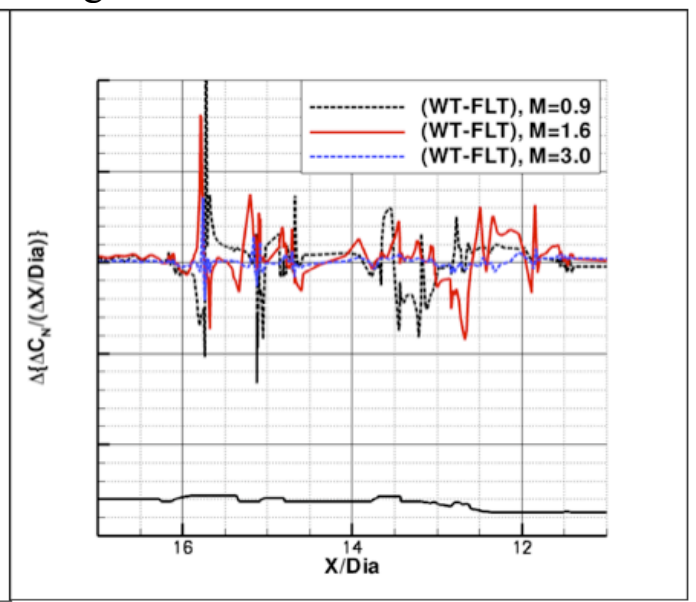

b)- Frustum region

Figure 32. Computed Re incremental effects on line-loads at various Mach number for the ADAC-3 (A106) at $\alpha=8^{\circ}, \Phi=0^{\circ}$.

The computed $\mathrm{C}_{\mathrm{AF}}$ and $\mathrm{C}_{\mathrm{N}}$ for the ADAC-3 (A106) configuration at $\alpha=8^{\circ}, \Phi=0^{\circ}$ for both the WT and FLT Re are shown in figure 33. It should be noted that these results are typical and that the general trends with respect to the Re effects remain the same for all examined roll angles. The results indicate a general reduction ( $\sim 5 \%$ or less) of the computed $\mathrm{C}_{\mathrm{AF}}$ at flight $\mathrm{Re}$ across the examined Mach range. Similarly, the computed $C_{N}$ at FLT Re also show a general drop in magnitudes, particularly over the low supersonic speed range $(1.05 \leq \mathrm{M} \leq 1.20)$ where they are reduced by as much as $7 \%$. In an effort to find the cause of this reduction, the solution for $\mathrm{M}=1.05$ was selected for further analysis and will be discussed next.

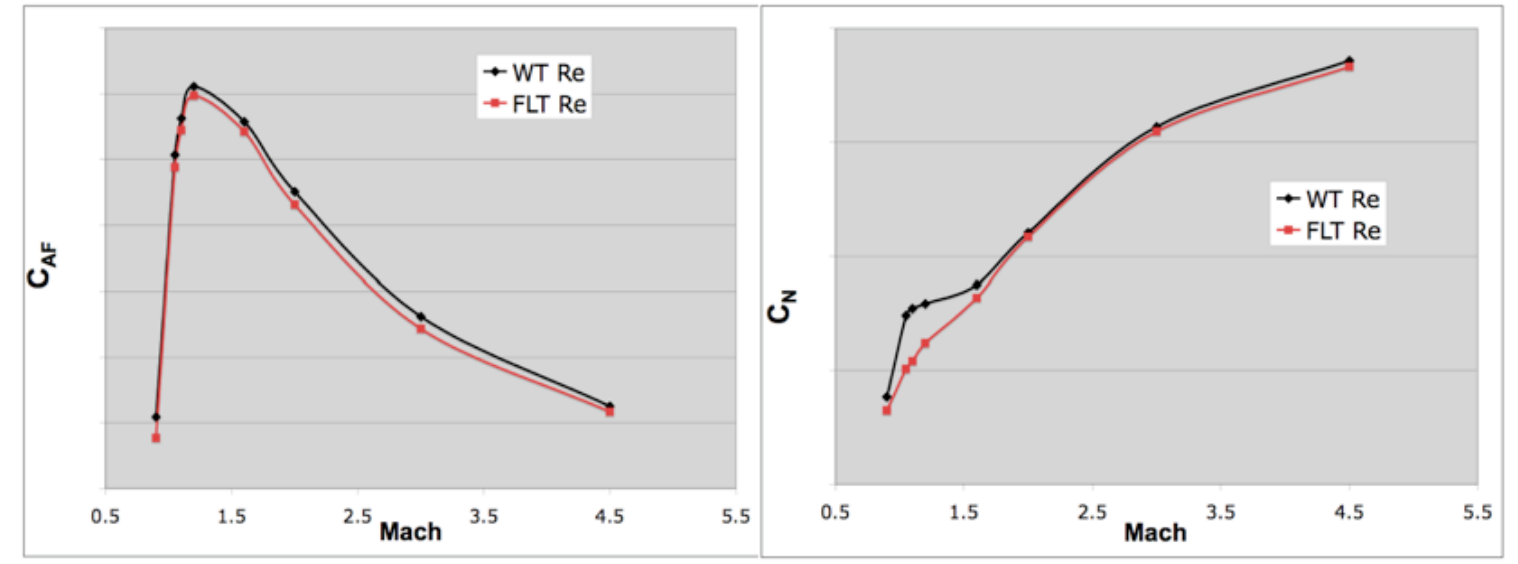

Figure 33. Computed $\mathrm{C}_{\mathrm{AF}}$ and $\mathrm{C}_{\mathrm{N}}$ at WT and FLT Re for the ADAC-3 (A106) at $\alpha=8^{\circ}$, $\Phi=\mathbf{0}^{\mathbf{0}}$. 
The computed flow features, consisting of surface $\mathrm{Cp}$ and off surface Mach contours, at $\alpha=$ $8^{\circ}, \mathrm{M}=1.05, \Phi=0^{\circ}$, WT Re and FLT Re, are shown in figure 34. Qualitatively, the effects of Re on the computed flow features appear to be very small over the front LAS/CEV region. However, such effects become significant over the aft upper stage and frustum region. For example, the computed surface Cp at FLT Re generally shows an expanded region on the surface that exhibit lower levels of $\mathrm{Cp}$ values (i.e., more negative) due to flow expansion in the aft region of the rings and the interstage/frustum juncture. In addition, the computed off surface Mach contours at FLT Re shows a trailing wake developing behind the camera on the leeward side of the frustum that doesn't occur in the results obtained at WT Re. These effects can generally be attributed to the expected thinner boundary layer at FLT Re and the local flow interaction with any protuberances.

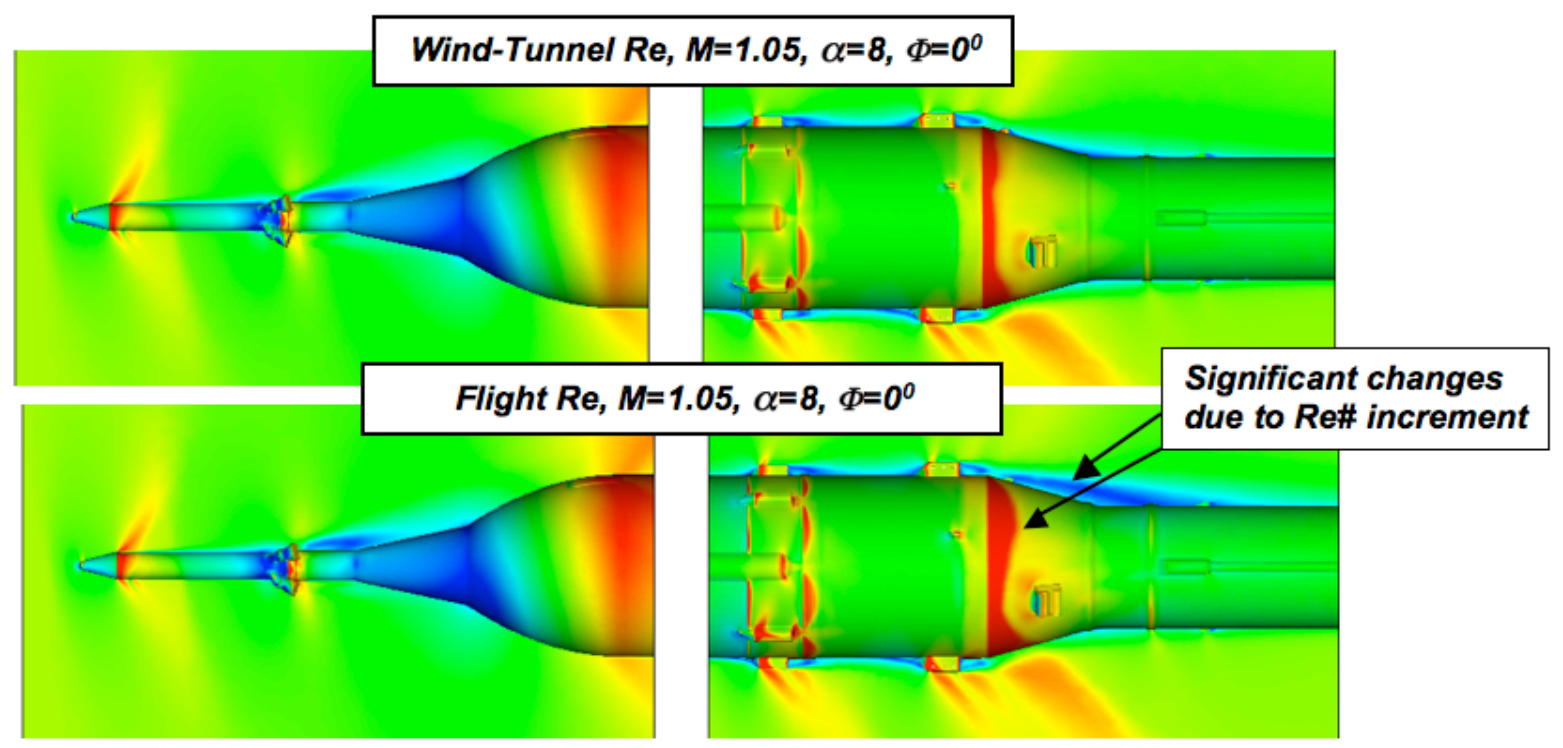

Figure 34. Computed surface $\mathrm{Cp}$ and off-surface Mach contours for the ADAC-3 (A106) at $M=1.05, \alpha=8^{\circ}, \Phi=0^{\circ}$, WT Re, portside view.

Furthermore, the cumulative line-loads $\left(\left(\mathrm{C}_{\mathrm{N}}\right)_{\mathrm{C}}\right)$ computed at $\alpha=8^{\circ}, \mathrm{M}=1.05, \Phi=0^{\circ}$, for both the WT Re and FLT Re, are shown in figure 35. The figure also shows the incremental effects on the computed $\left(\mathrm{C}_{\mathrm{N}}\right)_{\mathrm{C}}$ (denoted by $\mathrm{D}\left(\mathrm{C}_{\mathrm{N}}\right)_{\mathrm{C}}$ ) due to the Reynolds number. The results indicate a very small Re effects on computed $\left(\mathrm{C}_{N}\right)_{C}$ up to about mid upper stage. In general, the computed $\mathrm{D}\left(\mathrm{C}_{\mathrm{N}}\right)_{\mathrm{C}}$ ) results show that about one-half of the reduction in the computed $\mathrm{C}_{\mathrm{N}}$ at FLT Re occurs over the aft portion of the upper stage and the other half takes place over the first stage. As a result, the changes in the computed line-loads over the frustum ramp, although locally significant, does not appear to contribute much to the overall reduction in the computed $\mathrm{C}_{\mathrm{N}}$ at FLT Re. This overall reduction is found to be a cumulative effect due to the expected thinner boundary layer that results in a smaller viscous contribution to the normal force coefficient. 


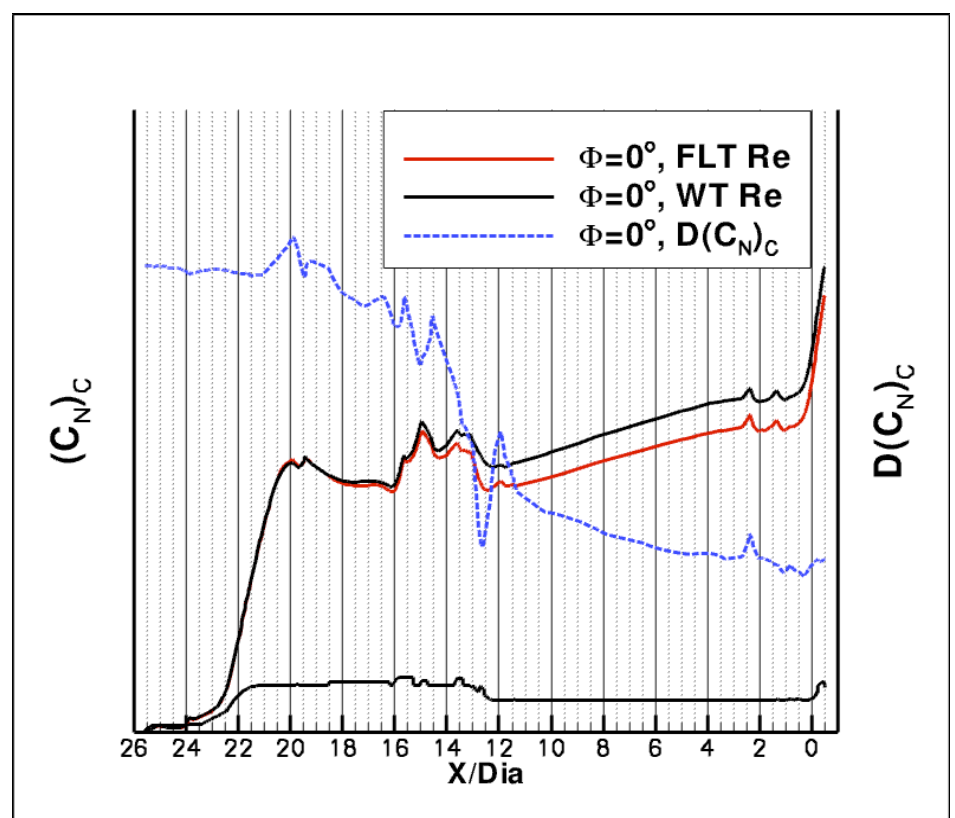

Figure 35. Computed cumulative line-loads at WT and FLT Re and their increment for the ADAC-3 (A106), $M=1.05, \alpha=8^{\circ}, \Phi=0^{\circ}$.

A sample rolling moment coefficients computed at $\mathrm{M}=1.6, \alpha=8^{\circ}$ for both WT and FLT Re are shown in figure 36 . With the exception at few roll angles, the computed $C_{R M}$ at FLT Re generally shows an increase relative to those computed at WT Re. This increase in the computed $\mathrm{C}_{\mathrm{RM}}$ at FLT Re becomes particularly important if it occurs at the maximum level and falls outside the roll control authority band. Such an increase in the computed $\mathrm{C}_{\mathrm{RM}}$ at FLT Re, though not validated, can have a significant effect on the design of an appropriate level of thrust requirements from the RoCS for the vehicle's roll control during ascent. Such analyses have been undertaken within the project and the details are reported in references 11 and 12 .

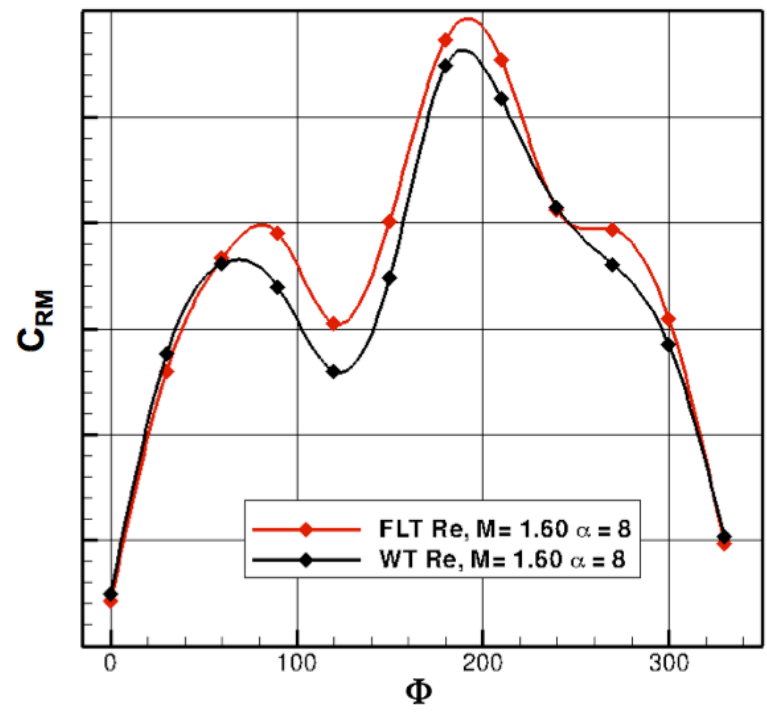

Figure 36. Effects of Reynolds number on computed $C_{R M}$ for the ADAC-3 (A106) at M $=1.6, \alpha=8^{\circ}$. 
An effort was also made to evaluate the overall aerodynamic performance of the evolving Ares-I vehicle. Sample results computed at $\alpha=7^{\circ}, \mathrm{M}=1.6$ and $\mathrm{WT}$ Re for $\mathrm{C}_{\mathrm{AF}}$, and $\mathrm{C}_{\mathrm{N}}$ are shown in figures 37 , as a function of roll angle, for the selected configurations. With the exception of the computed $\mathrm{C}_{\mathrm{N}}$ at $\Phi=180^{\circ}$ and $210^{\circ}$, the results for the ADAC-3 (A106) indicate a general increase in both $\mathrm{C}_{\mathrm{AF}}$ and $\mathrm{C}_{\mathrm{N}}$ relative to the prior ADAC-2B (A103) OML across the examined roll angles. Similarly the results computed at the same flow conditions for $\mathrm{C}_{\mathrm{RM}}$, and $\mathrm{CP}$ are shown in figure 38. The results indicate that the ADAC-3 (A106) configuration experiences an increased levels of maximum $C_{R M}$ at $\Phi=0^{\circ}$ and $180^{\circ}$ relative to the prior design cycle OML. The variation of the computed $\mathrm{CP}$ with roll angle remains similar for both configurations, however, the overall magnitude has decreased for the ADAC-3 (A103) OML.
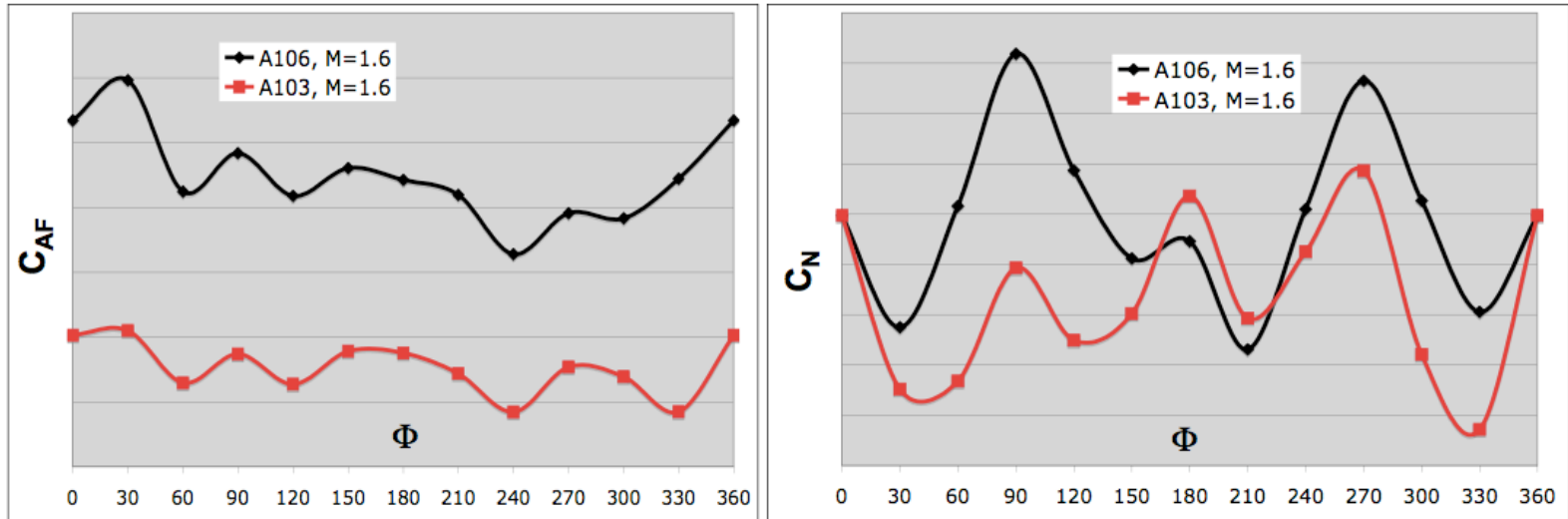

Figure 37. Computed $C_{A F}$ and $C_{N}$ for the ADAC-2B (A103) and ADAC-3 (A106) at $\alpha=$ $7^{\circ}, \mathrm{M}=1.6, \mathrm{WT}$ Re.
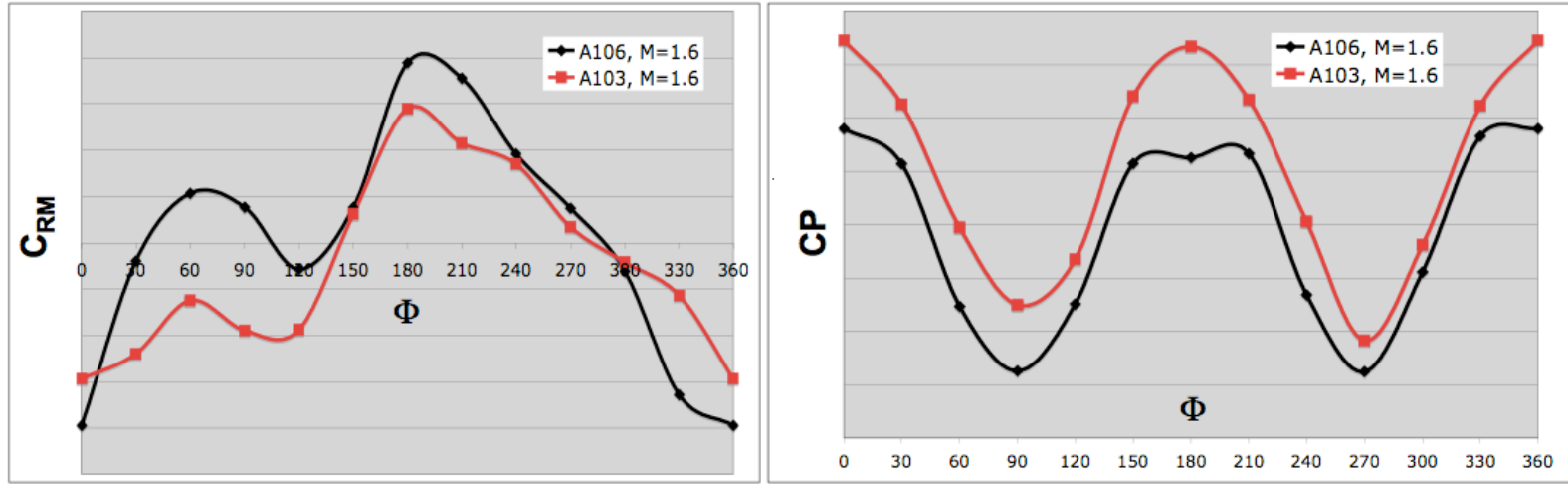

Figure 38. Computed $C_{R M}$ and $C P$ for the ADAC-2B (A103) and ADAC-3 (A106) at $\alpha=$ $7^{\circ}, \mathrm{M}=1.6, \mathrm{WT}$ Re.

The notion of strake concept, as a passive flow control device, to reduce and therefore improve the rolling moment of the vehicle during the ascent phase of the flight trajectory was addressed. The effectiveness of the strake as a roll control device was initially established during the aerodynamic analysis of the ADAC-2B (A103) configuration and the computational results were subsequently validated against complementary data obtained from wind tunnel testing. In the initial study and the follow up validation effort, the proper axial and circumferential location, height, size, and even the dual use of the device were identified [21]. Although not discussed here, the lessons learned from this study were used to assess the effectiveness of the device for 
improving the rolling moment of the ADAC-3 (A106) configuration. The configuration baseline grid was modified to incorporate the proposed strake geometry. This grid modification resulted in an increase of about 100,000 surface triangles and about $2 \times 10^{6}$ volume cells over the baseline grid. The location of the proposed strake and a representative computational grid are shown in figure 39. The strake geometry can essentially be thought of as a cropped delta wing that its presence would induce a rolling moment effects which would counterbalance those of the LH2 as a function of $\Phi$ (see figure 29). The computed $\mathrm{C}_{\mathrm{RM}}$, at $\alpha=7^{\circ}$ and $8^{\circ}, \mathrm{M}=1.6$ and WT Re, with and without the strake for the ADAC-3 (A106) configuration is shown in figure 40. The results with the strake indicate a significant reduction in the maximum $\mathrm{C}_{\mathrm{RM}}$ at both examined flow conditions. Representative comparisons of the computed results with the wind tunnel data for the configuration with and without the strake are reported in reference 23. Furthermore, the effectiveness of the strake as a roll control device for this configuration at flight Reynolds number was also verified.

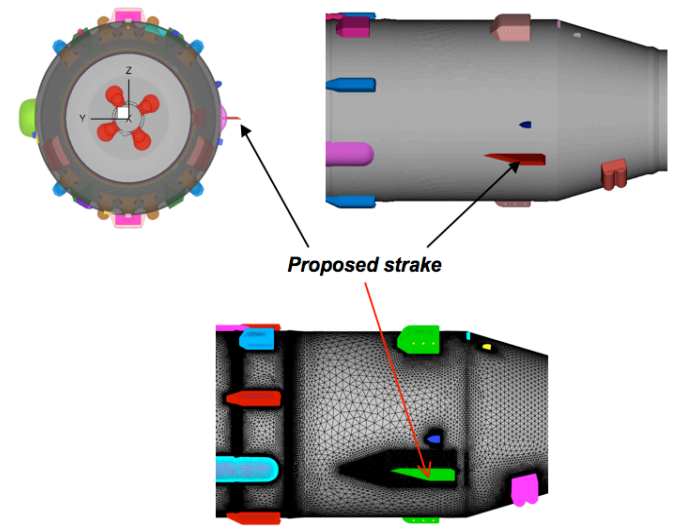

Figure 39. Shape, location and computational grid for the proposed strake on the ADAC-3 (A106).

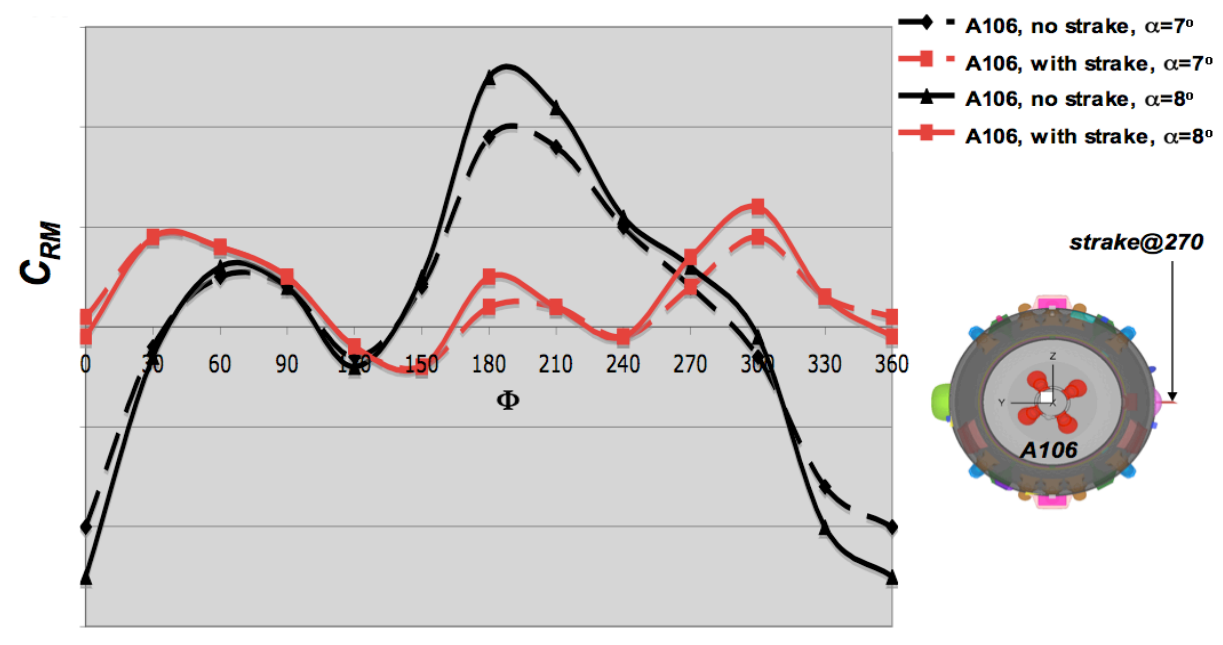

Figure 40. Computed $C_{R M}$ for the ADAC-3 (A106) with and without the strake at $M=$ $1.6, \alpha=7^{\circ}$ and $8^{\circ}$, WT Re. 


\section{Accomplishments}

An overview of the computational activities performed at the NASA Langley Research Center in support of the agency's Constellation program and in particular the Ares-I project are presented. The numerical results are based on the turbulent Navier-Stokes formulation and have been obtained from the USM3D flow solver for the evolving design cycles of Ares-I configuration at representative flow conditions pertinent to the ascent phase of the trajectory. Computations have been conducted at both the wind tunnel and flight Reynolds numbers. A summary of the accomplishments based on the results and analyses are as follows:

1- An efficient scripting process was developed for automating the solution generation and the associated convergence characteristic assessments to aid quality assurance, for a large number of configuration variations and flow conditions.

2- Different forms of the geometry representations from a simple clean to the vehicle with the full protuberances have been modeled for various vehicles design cycles.

3- Solution sensitivities to grid refinement have been addressed for a limited number of representative vehicle geometries.

4- The effects of different turbulence models on the computed aerodynamic characteristics were investigated in detail for selected configurations and flow conditions.

5- Computed flow solutions have been analyzed for aerodynamic features such as the surface $\mathrm{Cp}$, sectional and cumulative line-loads, the overall longitudinal/lateral aerodynamic characteristic, center of pressure, and for their corresponding trends with respect to angle of attack, Mach number, Reynolds number and the vehicle's roll angle.

6- The aerodynamic performance increments from the sub-scale wind tunnel model to fullscale vehicle flight Reynolds number have been quantified for limited numbers of solutions obtained at wind tunnel and flight Reynolds number.

7- An analysis process was established to isolate the aerodynamic contributions from individual or a group of protuberances towards the vehicle's total.

8- Demonstrated the feasibility of an approach used to estimate the aerodynamic impacts resulting from a possible repositioning/redistribution/addition/elimination of an individual or a group of protuberances on the vehicle's overall aerodynamic performance.

9- Established the viability of a new strake device to improve the vehicle's rolling moment characteristics at both the wind tunnel and flight Reynolds number.

10- As general practice within the project, all CFD solutions were completed and delivered in advance prior to the start of any experimental activities. Such practice was found to be useful for designing the wind-tunnel model hardware, its instrumentation sizing and strategic distribution, and test matrix development.

11- Numerical predictions have been verified against the complementary results obtained independently from other flow solvers for solution consistency.

12- Numerical predictions have been validated against the available experimental data that have been generated within the project over the past few years for various vehicles design cycles. 


\section{Concluding Remarks}

Feasibility of the present numerical method, as an engineering tool, has been demonstrated for the external flow aerodynamic analysis and design of such class of vehicles and flow conditions. The initial CFD data requirements, i.e. integrated line-loads and the aerodynamic effects resulting from sub-scale wind tunnel model to full-scale vehicle flight Reynolds number, were expanded during the course of this activity to include computational data analysis to support the need of other elements/groups within the project. These elements/groups include those supporting the debris and venting analysis, Orion loads, protuberance component loads, wind-tunnel model design/instrumentation, GN\&C, and database development. In addition, USM3D data was used to study the impacts resulting from a possible repositioning, redistribution, resizing, addition, and/or elimination of an individual or a group of protuberances on the vehicle's overall aerodynamic performance. For example, it was demonstrated that the addition of a new strake device would cause a significant reduction in the vehicle's maximum rolling moment coefficient during ascent and its effectiveness was later validated by wind tunnel measurements. The USM3D results and analyses also indicated that the SA turbulence model was generally most accurate, robust, and numerically efficient as compared to other two equation models studied for the present application.

\section{Follow-on Efforts}

In spite of many efforts made during the course of these investigations to address the solution sensitivities to the grid refinement: a more systematic approach is presently underway to tackle the issue by providing a measure to assess the goodness (i.e., error/uncertainty band) of the A106 baseline grid and the resulting predictions for the aerodynamic force/moment coefficients. This effort was made possible mainly due to the recent improvements and increase in the supercomputing power (Pleiades system) at the NAS facility located at the Ames Research Center. The grid densities used in this study ranged from $30 \times 10^{6}$ to $270 \times 10^{6}$ cells, and the computations are focused on conditions at flight Re with no propulsion effects. This study will explore the following issues:

- Establish a process to address the solution sensitivities to grid refinement for the Ares-I class of vehicles.

- Grid requirement for power off cases at flight Re.

- Asymptotic convergence behavior of the force/moment coefficients with grid refinement at various vehicle roll angles and Mach numbers.

\section{Acknowledgement}

The authors would like to acknowledge the contributions of Robert Hall, Paul S. Pao, Mohagna Pandya, Jamshid Samareh, Karen Deere, Norma Farr, Mike Wiese, Veer Vatsa, Robert Biedron, Sudheer Nayani, Alaa Elmiligui, Shamsa Hasan, and James Luckring, and the late Shahyar Pirzadeh at the NASA LaRC. Also, the authors would like to express our utmost appreciation to the support from the Ares Program Office management at LaRC, Goetz Klopfer and the NASA's Advanced Supercomputing complex personnel of the Ames Research Center. 


\section{References}

1. NASA's Exploration Systems Architecture Study. NASA-TM-2005-214062, Nov. 2005.

2. Huebner, L. D.; Smith, R. M., Campbell, J. R.; and Taylor, T. L. "Ares-IX Flight Vehicle Similitude to the Ares I Crew Launch Vehicle". IAC-08-D2.6.7, 59 ${ }^{\text {th }}$ International Astronautical Congress, Sept. 29- Oct. $3^{\text {rd }}$ 2008, Glasgow United Kingdom.

3. Frink, N. T.; Pirzadeh, S. Z.; Pandya, M.J.; Bhat M.K.; " The NASA Tetrahedral Unstructured Software System". The Aeronautical Journal, Vol. 104, N0. 1040, October 2000, pp. 491-499.

4. Alexandrov N.M., Atkins H.L., Bibb K.L., Biedron R.T., Carpenter, M.H., Gnoffo P.A., Hammond D.P., Jones W.T., Kleb W.L., Lee-Rausch E.M., Nielsen E.J., Park M.A., Raman, V.V., Roberts T.W., Thomas J.L., Vatsa V.N., Viken S.A., White J.A., Wood W.A., "Team Software Development for Aerothermodynamic and Aerodynamic Analysis and Design", NASA TM-2003-212421, November 2003.

5. P.G. Buning, W.M. Chan, K.J. Renze, D.L. Sondak, I.-T. Chiu, and J.P. Slotnick, OVERFLOW User's Manual, Version 1.6ab, 26 January 1993, NASA Ames Research Center, Moffett Field, CA, Jan. 1993.

6. Robert M. Hall, Holland, S.D.; Blevins, J.A. "Aerodynamic Characterization Overview of a Modern Launch Vehicle", 49th AIAA Aerospace Sciences Meeting including the New Horizons, AIAA Paper No. 2011-xxxx, Orlando, FL.

7. Pamadi, B.N.; Pei, J.; Covell, P.F.; Favaregh, N.M.; Gumbert, C.R. "Aerodynamic Analyses and Database Development for the Lift-off Transition and First Stage Ascent of Ares-I A106 Vehicle". 49th AIAA Aerospace Sciences Meeting including the New Horizons, AIAA Paper No. 2011-xxxx, Orlando, FL.

8. Hemsch, M.F., Walker, E.L. "The Crucial Role of Error Correlation for Uncertainty..." 49th AIAA Aerospace Sciences Meeting including the New Horizons, AIAA Paper No. 2011xxxx, Orlando, FL.

9. Tomek W.G.; Erickson, G.E.; Hanke, J.L.; Pinier, J.T. "Overview of Experimental Investigations for Ares Launch Vehicle Development", 49th AIAA Aerospace Sciences Meeting including the New Horizons, AIAA Paper No. 2011-xxxx, Orlando, FL.

10. Pao, S. P., Deere, K.A.; Abdol-Hamid, K.S. "Establishing Approaches to Modeling the AresIX and Ares-I Roll Control System..."49th AIAA Aerospace Sciences Meeting including the New Horizons, AIAA Paper No. 2011-xxxx, Orlando, FL.

11. Deere, K. D., Elmiligui, A.A.; Abdol-Hamid K.S. "Computational Analysis of Ares-I Roll Control System Jet Interaction" 49th AIAA Aerospace Sciences Meeting including the New Horizons, AIAA Paper No. 2011-xxxx, Orlando, FL.

12. Pandya, M.J.; Frink, N.T.; Abdol-Hamid, K.S.; Samareh, J.A.; Parlette, E.B. "Enhancements to NASA TetrUSS for Constellation Program", 49th AIAA Aerospace Sciences Meeting including the New Horizons, AIAA 2011, Orlando, FL.

13. Spalart. P.R., Allmaras, S.R.: A One-Equation Turbulence Model for Aerodynamic Flows. AIAA Paper No. 1992-0439.

14. Jones, W. P., and Launder, B. E., "The Prediction of Laminarization With a Two-Equation Model of Turbulence," Int. J. Heat \& Mass Transf., vol. 15, no. 2, Feb. 1972, pp. 301-314.

15. Menter, F. R., "Improved Two-Equation k-omega Turbulence Models for Aerodynamic FlowsÓ, NASA TM103975, October 1992. 
16. Samareh, Jamshid, A. "GridTool: A Surface Modeling and Grid Generation Tool, Proceedings of the Workshop on Surface Modeling, Grid Generation, and Related Issues in CFD Solutions, NASA Lewis Research Center, Cleveland, OH, NASA CP-3291, 1995, May 9-11, 1995.

17. Pirzadeh, Shahyar, Z. "Advanced Unstructured Grid Generation for Complex Aerodynamics Applications". AIAA Paper No. 2008-7178, August 2008.

18. Abdol-Hamid, Khaled S.; and Ghaffari, Farhad; Computed Turbulent Ascent Aerodynamic Characteristics of DAC1 Configuration. Ares-I Project, Ares-Aero-0007, May 2007.

19. Abdol-Hamid, Khaled S.; and Ghaffari, Farhad; Pao, S. P.; Deere, Karen; Parlette, Edward, "Computed Turbulent Ascent Aerodynamic Characteristics of ADAC-2A Configuration". NASA Ares-AD-TA-0005, July 2007.

20. Abdol-Hamid, Khaled S.; Ghaffari, Farhad; Pao, S. P.; Deere, Karen, A.; Elmiligui Alaa; Parlette, Edward. Computed Turbulent Ascent Aerodynamic data analysis for the proposed Ares I ADAC-2B (A103) Configuration. Ares-I Project, NASA Ares-AD-TA-0012, May 2008.

21. Abdol-Hamid, Khaled S.; Ghaffari, Farhad; Parlette, Edward; and Hasan Shamsa. Ascent Aerodynamic Data Analysis of the Proposed Ares-I A106 Configuration Based on the Turbulent Navier-Stokes Computations. NASA Ares-I Project, 2010, presently under review.

22. Samareh, Jamshid, A. "Discrete Data Transfer Technique for Fluid-Structure Interaction", AIAA Paper No. 2007-4309.

23. Erickson, G. E., and Wilcox, F. J. "Ares I Aerodynamic Testing at the NASA Langley Unitary Plan Wind Tunnel", 49th AIAA Aerospace Sciences Meeting including the New Horizons, AIAA 2011, Orlando, FL.

24. Pinier, J.,"Ares I Aerodynamic Testing at the Boeing Polysonic Wind Tunnel, . 49th AIAA Aerospace Sciences Meeting including the New Horizons, AIAA 2011, Orlando, FL.

25. Pao, S. P.; Vatsa, V. N.; Abdol-Hamid, K. S., Pirzadeh, S.; Samareh, J. A.; Klopfer, G. H.; Taft, J.R.; and Parlette, E. B.: Best Practice for Ascent Aerodynamics Analysis for the Ares I Configurations. Special Session at 55th JANNAF Propulsion Meeting in Boston, MA. May 12-16, 2008.

26. Bauer, S. X., Krist, S. E. and Compton, W. B. "Generation of the Ares I-X Flight Test Vehicle Aerodynamic Data Book and Comparison To Flight", 49th AIAA Aerospace Sciences Meeting including the New Horizons, AIAA 2011, Orlando, FL.

27. Peter F. Jacobs, David T. Chan, Francis J. Capone, and Jeremy L. Hanke, "0.01-Scale CLV ADAC-2B (A103) Pressure Model Testing in the NASA Langley Research Center National Transonic Facility from Mach 0.5 to Mach 1.08", ARES-AD-TA-0015, August 1, 2008.

28. Lamar, J.E. and Abdol-Hamid, K.S.: USM3D Unstructured Grid Solutions for CAWAPI at NASA LaRC. AIAA Paper No. 2007-0682. 